\title{
Macro X-Ray Fluorescence (MA-XRF) scanning, multi- and hyperspectral imaging study of multiple layers of paintings on paneled vault in the church of Le Quillio (France)
}

\author{
K. Laclavetine ${ }^{1,2}$, D. Giovannacci ${ }^{3, *}$, M. Radepont ${ }^{1}$, A. Michelin ${ }^{1}$, , A. Tournié ${ }^{1}$, 0. \\ Belhadj ${ }^{1}$, Ch. Andraud ${ }^{1}$, W. Nowik 3 ,* \\ ${ }^{1}$ CRC-CRCC, CNRS USR 3224, MNHN, MiC, 36 rue Geoffroy-Saint-Hilaire, MNHN CP21, 75005 Paris, \\ France \\ ${ }^{2}$ Ecole Pratique des Hautes Etudes (EPHE), Université Paris-Sciences-et-Lettres (PSL), 4-14 rue Ferrus, \\ 75014 Paris, France \\ ${ }^{3}$ CRC-LRMH, CNRS USR 3224, MiC, 29 rue de Paris, 77420 Champs-sur-Marne, France \\ *Corresponding authors: david.giovannacci@culture.gouv.fr, witold.nowik@culture.gouv.fr
}

\begin{abstract}
During initial conservator's investigation of paneled wooden vault of the church in Le Quillio, 17th century paintings, hidden behind painted canvas nailed on the panels were discovered. A closer look on these paintings and some exposure windows showed the presence of an older paint layer. This layer corresponds to the first vault decoration, dating back all the way at the end of 15th century, existence of which was attested by written sources. However, the conservation state of the original pictorial layer was unknown, so it was not possible to make a decision to uncover it without further information acquired, preferably, noninvasively. Examination of different layers was performed by extracting, processing and cross-referencing the information from the complementary data obtained from MA-XRF scanning as well as multi- and hyperspectral imaging. This allowed to characterize the mineral composition of different layers and to attribute them respectively to the end of 15 th century original painting, the 17 th century overpaint and to the later 19th century interventions corresponding rather to a large retouching or restoration. Our study also showed the particularities of the mounting of panels, as some parts on the first decoration's paint seem to be partially discontinued between successive panels and may attest to the exchange of panels between different parts of the vault. This pilot study was conducted on an only small part of the large vault $(0.4 \%$ of the $32 \mathrm{~m}^{2}$ ). Further, more extensive investigations will be required to better understand this complex object and its complex history.
\end{abstract}

\section{INTRODUCTION}

The chapel of Rosary, located on the Southern side of the church of Notre-Dame-de-laDéliverance in Le Quillio (Bretagne, France), was built between the end of the 15th century and the beginning of the 16th century. It was covered by a wooden vault of $5.20 \mathrm{~m}$ long, $6.50 \mathrm{~m}$ wide and $4.00 \mathrm{~m}$ high. The $32 \mathrm{~m}^{2}$ of vault surface is composed of 529 panels. ${ }^{[1]}$ In 1869 , the original vault was covered with canvas painted by Raphaël Donguyen. These canvases hid former paintings done by Louis Le Corre in 1686. The 19th century canvas, removed during a recent restoration works, represents a series of Saints and Holy Virgin in the style characteristic of this period. These canvases reproduce in a simplified way the pictorial program from the 17th century. ${ }^{[2]}$

Restoration works, during which it was possible to take a closer look at Le Corre painting, allowed identifying the presence of another, underlying, painting in areas where lacunas of more modern painting showed the difference of color or gloss. The uncovering done on the forehead of the Virgin, whose head was straight-positioned, displayed a large part of another face's right eye, with the head leaning to the left. This underlying painting, probably the original one, could have been executed on the vault just after its construction between the end of the 15th century and the beginning of the 16th century. Due to this fact, it was interesting to investigate if the conservation state of underlying painting would be satisfying and the extent of its remains were large enough to take the decision to uncover it.

The approach for the evaluation of the remaining original painting in Le Quillio had to fit several constraints: capability to display the extent of underlying painting and clearly differentiate it from overlaying layers, possibility to cover large examined surface in relatively short time, as well as transportability of the instrumentation on site and work on the scaffolding. In addition, being twisted or curved, the wooden panels required a very skilled approach. Several imaging and spectroscopic techniques could be applied to serve the purpose; most of them are mainly based on the detection 
of visible, infrared or X-ray radiations. ${ }^{[3-10]}$ Moreover, a recent study underlines the efficiency of photoacoustic detection for such investigation. ${ }^{[11]}$

Visible (VIS) light and near infrared (NIR) photographies are used for macroscopic observation. In addition, NIR photography highlights the IR reflection properties of materials. ${ }^{[12]}$ For example, it helps in the observation and study of carbon black underdrawings, which does not reflect IR radiation, showing dark pattern on the NIR image. ${ }^{[13-14]}$ VIS and NIR photographies are in situ non-invasive multispectral techniques.

Moreover, VIS and NIR images are used to produce false color PCA composite images. The false color PCA composite images are created by digitally editing the VIS and NIR images of the same subject. These images linked the visible color of the materials with their IR reflection properties. They are useful to distinguish the different compounds present on the painting.

Reflectance imaging spectroscopy or hyperspectral imaging spectroscopy is a powerful technique for the non-invasive study of cultural heritage objects. It combines imaging and reflectance spectrometer systems in the wavelength domain going from visible to short wave infrared $(400-2500 \mathrm{~nm})$. The image recorded is defined by two spatial dimensions $(\mathrm{x}, \mathrm{y})$ and one spectral dimension $(\mathrm{z})$, meaning that each pixel of the image contains diffuse reflection spectrum of the visible and/or infrared spectral ranges. Spectral images contain spectral features, which are linked to compositional information and can hence be used to generate useful chemical maps. Paintings or illuminated manuscripts have been studied using hyperspectral imaging. ${ }^{[12,}$ 15-16] It reveals preparatory drawings or artist modifications that can no longer be seen and helps to distinguish the materials used on large surfaces.

X-ray fluorescence spectroscopy (XRF), being non-destructive and non-invasive, is a modern analytical technique to study materials used in cultural heritage objects. The imaging possibilities offered by MA-XRF scanners are particularly interesting for paintings, ${ }^{[17]}$ and the technique proved to be especially useful to visualize hidden layers due to good penetration of X-rays in matter. ${ }^{[18-19]}$

The aim of the study was to detect the extent of the original underlying painting. For that, it was necessary to find chemical elements corresponding to the pigments present on wooden panels and to differentiate between original and later pictorial layers by characterizing them according to their behavior in VIS, NIR and X-rays. All the analytical techniques used were expected also to contribute to the localization of restoration work done on the 17 th century overlying painting before the covering of vault with painted canvas in 19th century In this pilot work, done on the series of unmounted panels, we strived to evaluate the methods in terms of their applicability to the research of underlying painting on the whole vault, considering their respective informative outcomes and surface coverage capacities.

\section{MATERIALS AND METHODS}

\subsection{The painted panels' sample}

A small part of the painted vault, consisting of three wooden panels ( $\mathrm{W} \sim 91 \mathrm{~cm}, \mathrm{H} \sim 8$ to $13 \mathrm{~cm}$ ) (Figure 1), was transferred to the laboratory and analyzed with different imaging and spectroscopic techniques, detailed below.

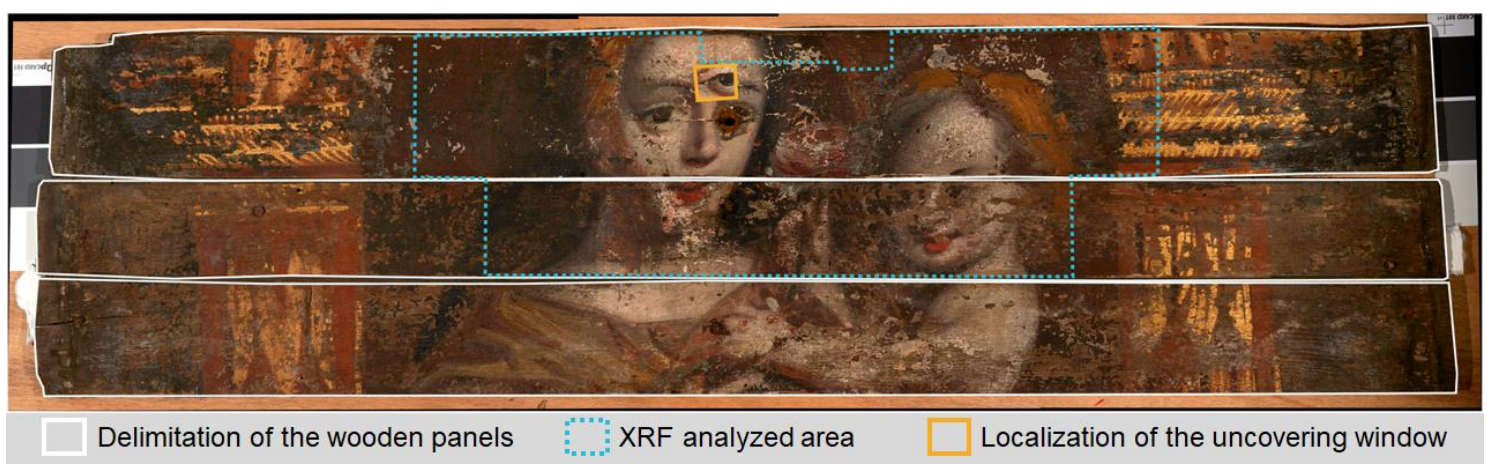

FIGURE 1 The three wooden panels studied with covering areas of macro X-ray fluorescence (MA-XRF) and spectral imaging. The wooden panels are delimitated in continuous white lines, the rectangular uncovering window showing an eye of underlying portrait is delimited in continuous orange, and X-ray fluorescence (XRF) analyzed area in dotted blue lines. 


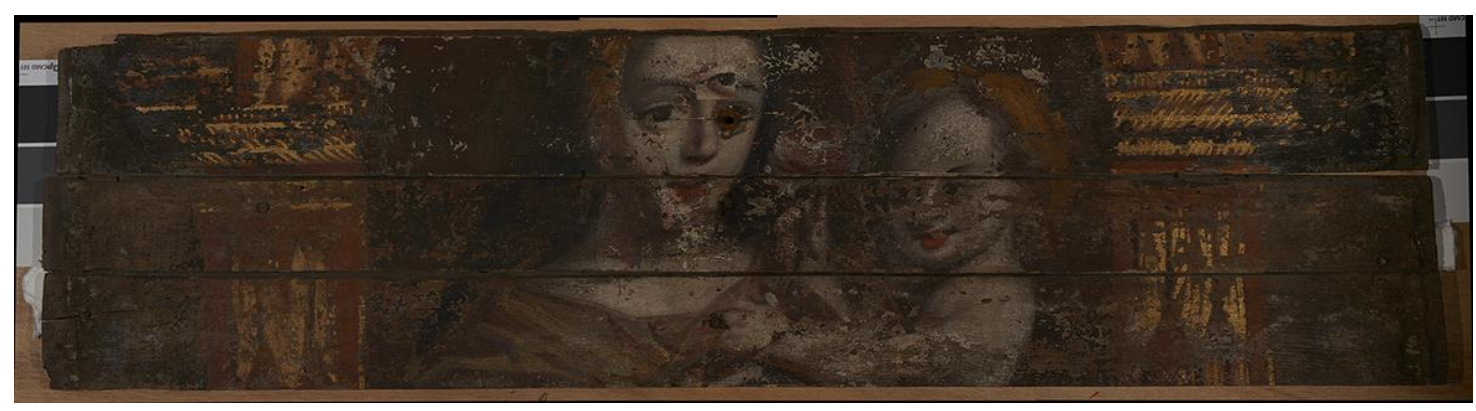

FIGURE 2 Calibrated visible (VIS) image of the three painted wooden panels.

\subsection{VIS and NIR photographies}

For VIS and NIR photographies, a Nikon unfiltered CCD camera (model D800) was used with an f11 aperture, 1/60 s shutter speed at 200 ISO. Two flashlights were positioned at the $45^{\circ}$ angle on each side of the painted panel sample at the same distance. The lighting homogeneity was controlled with the use of a Gossen ambient light meter (model Digipro F). For VIS photography, the BG38 filter was used to cut UV and IR radiations while, for NIR photography, the RG780 filter was placed in front of the camera in order to cut UV and visible spectrum. Finally, the images were examined with Capture One software and calibrated using QP card charts. As the painting covering the three wooden panels appeared quite dark on the VIS photography (Figure 2), we adjusted the brightness levels of the VIS image in order to enhance the contrast of the painting (Figure 1).

\subsection{The false color PCA composite images}

The false color PCA composite images are digitally generated with the VIS and NIR images using ImageJ software. Each image is composed of three channels (red, green and blue). First, the VIS and NIR channels are put together in a composite image, named "stack". Then, this stack of channels is processed with the plugin "Multivariate Statistical Analysis of image series" which allows reducing its dimensions. ${ }^{[20]}$ Stack dimensionality reduction is performed according to Principal Components Analysis (PCA). The different channels of the new stack are the principal components (or the factorial images) of the original stack. Based on the new stack, a PCA image of three channels is generated. After that, this PCA image is processed with the plug-in DStretch. ${ }^{\text {[21-22] }}$ DStretch implements on the PCA image a decorrelation stretch based on color space (YDS, $\mathrm{LAB}$, etc.) and it produces a new set of false color PCA images.

\subsection{HSI spectroscopy)}

Hyperspectral images were acquired with two different imaging devices for the two spectral ranges under study but using the same pushbroom scanning-method systems purchased from Specim Corp. (Finland). The visible and near infrared range (VNIR) imager was a Specim HS camera operating from 400 to $1000 \mathrm{~nm}$ equipped with an ImSpector V10E2/3" spectrograph combined with an Imperx IPX-2M30 CDD detector (1600 spatial x 1200 spectral pixels' matrix). The second image device covered the short-wave infrared (SWIR) range from 970 to $2500 \mathrm{~nm}$. This system combined an ImpSector N25E 2/3" spectrograph coupled with a cooled MCT detector ( $9.6 \mathrm{~mm}$ detector with 320 spatial x 256 spectral pixels' matrix).

The objective lenses used for the VNIR and SWIR cameras were OLE23 (focal length of $23 \mathrm{~mm}$ ) and OLES56 (focal length of $56 \mathrm{~mm}$ ), respectively. Spectral samplings were of $3 \mathrm{~nm}$ for the VNIR and $10 \mathrm{~nm}$ for the SWIR detectors. Spatial resolutions were $1 \mathrm{~mm}$ (VNIR) and $0.3 \mathrm{~mm}$ (SWIR) for the scanning working distances $600 \mathrm{~mm}$ and $550 \mathrm{~mm}$ respectively.

Two ramps of three $35 \mathrm{~W}$-halogen lamps (one on each side of the detector) were used as illumination sources. They were fixed together with the camera and moved along a motorized bar. After the hyperspectral image scanning of the panel, a diffuse white reference (Spectralon $\AA$, 99\% reflectance) covering the entire field of view of the detector was scanned to flat-field and calibrate the data. A dark reference was also acquired at each acquisition with a built-in shutter in the aim of quantifying the detector electronic noise.

Different ways to map materials in hyperspectral imaging were used. Mapping specific materials is generally more difficult than with other spectroscopic techniques because the characteristic features are often less obvious and a general appearance of the spectrum is difficult to map without interfering with other materials. It is sometimes necessary to process the data cube once it has been converted to pseudo- 
absorbance, calculating $\log (1 / \mathrm{R})$, or once the first derivative has been calculated. This process allows highlighting a characteristic feature of a material. The material's maps were obtained by supervised methods, i.e. by providing one or more reference spectra.

On one hand, we compared reference spectra to those from the data cube using spectral difference. Several functions exist, such as the Spectral Angle Mapper $(\mathrm{SAM})^{[23]}$ or the Euclidean distance. We used the SAM which calculates the angle between two spectra considered to be vectors. The SAM is mainly affected by shape difference between the spectral curves. ${ }^{[24]}$ Studying the spectral shape variation generally gives enough information concerning chemical properties of materials to be able to classify spectra in regards to its components. The SAM map shows the spectra closest to the reference. The threshold was chosen looking at the histogram of distance and choosing the closest peak to the origin if more than one.
On the other hand, for mixture or for spectra in the SWIR range, a Mixture Tuned Matched Filtering (MTMF) classification was preferred. This linear unmixing algorithm is an effective tool for identifying the presence and abundance when the spectrum presents features from several materials. ${ }^{[25-26]}$

The reference spectra used here were directly extracted from the data cube in a specific material or they were end-members determined thanks to the hourglass paradigm developed by Boardman et al. ${ }^{[25]}$ and implemented in the ENVI image processing program. This way to process is very widespread in the analysis of cultural heritage objects. ${ }^{[27]}$

Hyperspectral maps should be considered carefully as it is possible that different materials may be mapped at the same time (due to the proximity of the spectra to the reference, for example). So, the validity of the maps was checked by extracting reflectance spectra from the data cube.
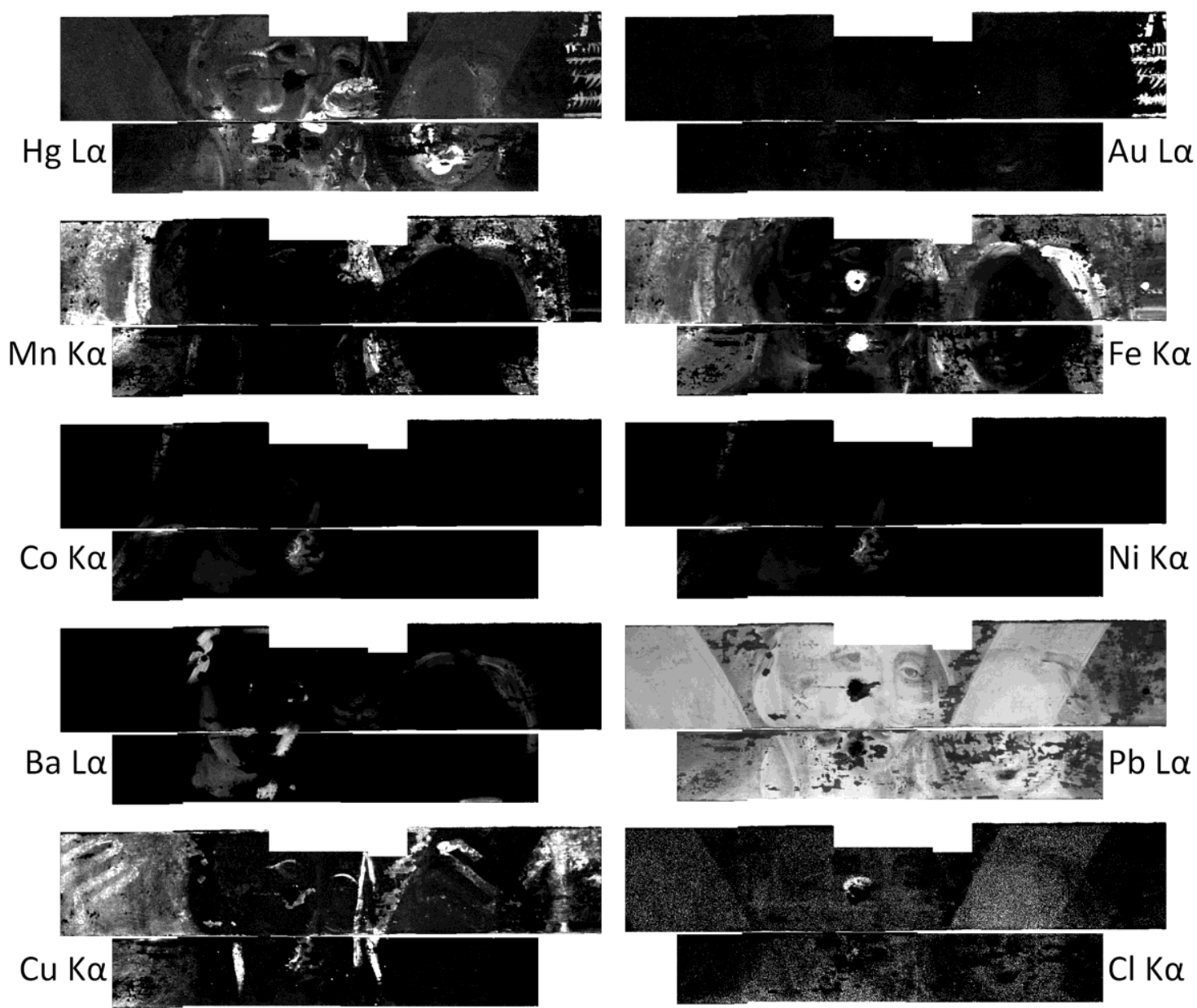

FIGURE 3 X-ray fluorescence (XRF) maps of different chemical elements of interest (Ka or L $\alpha$ lines). 


\subsection{MA-XRF scanning}

Elemental cartographies were performed with the M6 Jetstream XRF scanner (Bruker) ${ }^{[19,28]}$ containing an X-ray tube with a rhodium anode at $50 \mathrm{kV}$ and $600 \mu \mathrm{A}$ with a $100 \mu \mathrm{m}$ thick beryllium window. Polycapillary optic was used to focus the X-ray beam. The X-ray detector was a $60 \mathrm{~mm}^{2}$ SDD with a Peltier cooler, which 4096 channels were divided into $40 \mathrm{keV}$ with a maximum count rate of $275 \mathrm{kcps}$. The target was placed horizontally at an average working distance of $2.4 \mathrm{~cm}$. The beam diameter was $450 \mu \mathrm{m}$, the distance between each point was $450 \mu \mathrm{m}$ and the time per point $100 \mathrm{~ms}$. Data were processed with the Esprit software (Bruker) and Datamuncher developed by Alfeld. ${ }^{[29-30]}$ The wooden panels presented several flight holes made by xylophages. In order to protect the other wooden cultural heritage objects conserved in the room where the XRF system was implemented, all XRF analyses were performed through hermetically sealed polyethylene bags in which panels were slipped. Preliminary tests showed that the polyethylene covering of wood panels did not affect acquisitions conditions and obtained results.

\section{RESULTS AND DISCUSSION}

In this study, MA-XRF maps were made on a limited area, panel by panel, including faces of the Virgin and the Child (Figure 1), because already this part (composed of 9 individual areas) needed about 14 hours to be scanned. Figure 3 shows the original element maps obtained by XRF.

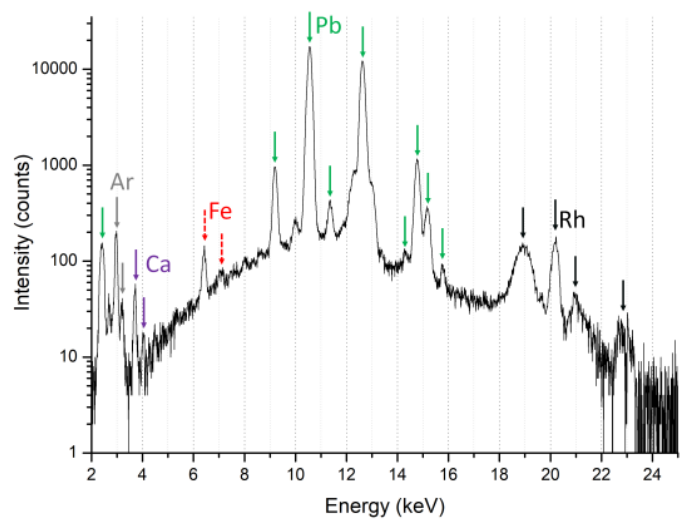

FIGURE 4 X-ray fluorescence (XRF) sum spectrum (60 pixels) extracted from the forehead of the Virgin showing the presence of lead.

Hyperspectral and multispectral techniques were applied on the three panels together. These techniques, allowing faster imaging and covering a larger area in relatively short time: about 10 min for multispectral and $75 \mathrm{~min}$ for both hyperspectral wavelength domains. These techniques were used to confirm, complete and extrapolate the XRF results on larger area of examined panels.

\section{17TH CENTURY PAINT AND 19TH CENTURY RESTORATIONS}

As stated before, painting executed by Louis Le Corre in $1686^{[31-32]}$ and its later 19th century restorations were discovered hidden behind painted canvas nailed on the panels. Lead white was identified for the carnation of the Virgin and the Child by the presence of lead in XRF spectra (Figure 4) and confirmed by hyperspectral analysis showing the presence of hydrocerussite $\left(\mathrm{Pb}_{3}\left(\mathrm{CO}_{3}\right)_{2}(\mathrm{OH})_{2}\right)$ which, along with cerussite $\left(\mathrm{PbCO}_{3}\right)$, is present in this artificial pigment. On reflectance spectra, hydrocerussite can be identified in particular by the presence of a narrow absorption feature centered near $1445 \mathrm{~nm}$ corresponding to the first overtone of $-\mathrm{OH}$ stretching vibration (Figure 5). The best map of the hydrocerussite distribution was obtained by converting the SWIR hyperspectral cube of reflectance data to pseudo absorbance $(\log (1 / \mathrm{R}))$ and calculating the distance (here SAM) from a hydrocerussite reference extracted from the data cube to the other cube spectra. The resulting map (Figure 6) shows the spectra closest to the reference. The SAM map allows visualizing only the lead of the most surface layer of the painting. This gives us the possibility to access the information of surface materials only, without that of the underlying layers. However, the detection of hydrocerussite by hyperspectral data was sometimes difficult in some areas (the Virgin hair or the lower part of her face, for example) because of the low signal intensity, likely caused by the presence of black materials absorbing in the region of hydrocerussite characteristic features.

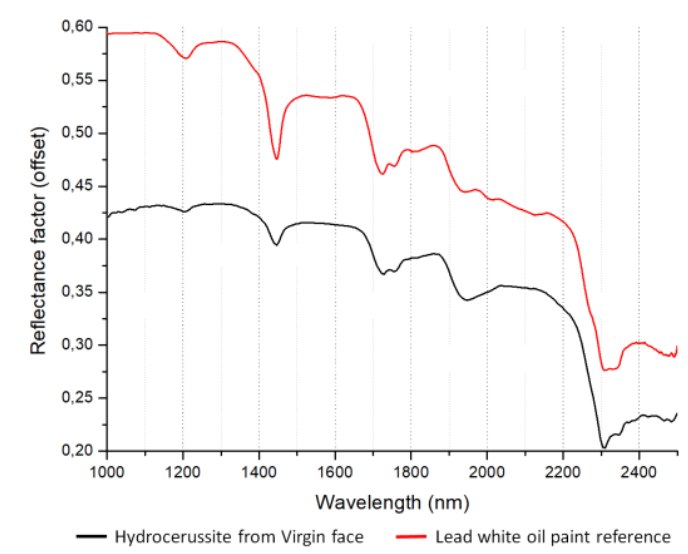

FIGURE 5 Short-wave infrared (SWIR) reflectance spectrum (extracted from 400 pixels) in the Virgin face showing the presence of hydrocerussite compared to a reference of lead white oil painting. 


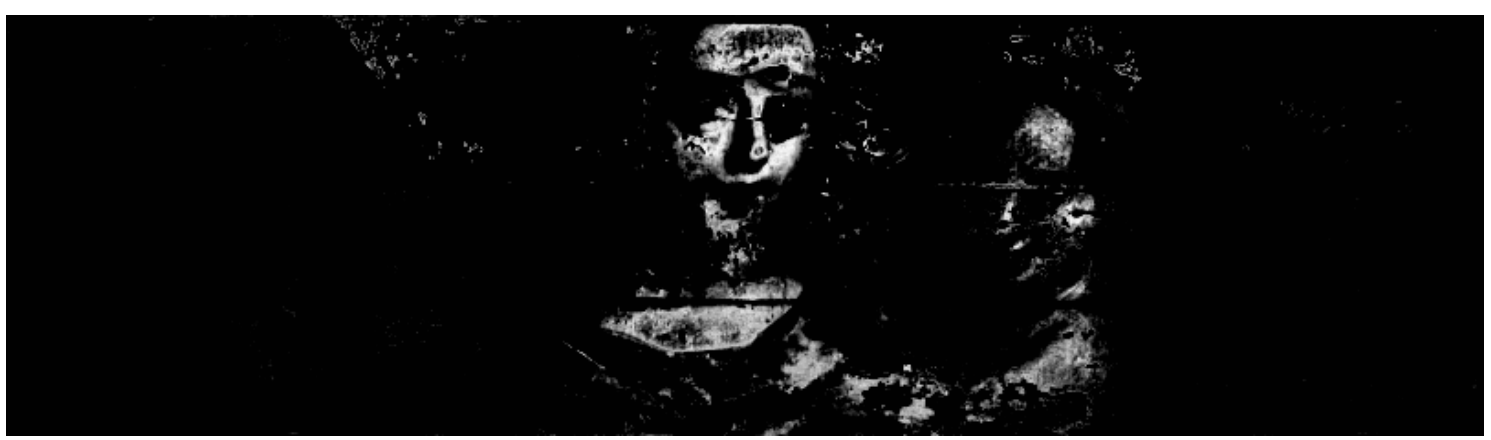

FIGURE 6 Spectral Angle Mapper (SAM) map of the short-wave infrared (SWIR) image cube converted in pseudo-absorbance $(\log (1 / \mathrm{R}))$ showing the presence of hydrocerussite on the surface. A spectrum extracted from the Virgin face is used as reference spectrum.

Vermilion or cinnabar was used for the lips, as deduced from the XRF results showing the presence of mercury $(\mathrm{Hg})$ (Figures 7 and 8) and from the reflectance spectra showing absorption bands with a sigmoid-shape characteristic of semiconductor materials such as minium, realgar, cinnabar and vermilion (Figures 9 and 10). The reflectance spectra have an inflection point around $615 \mathrm{~nm}$ which is slightly shifted compared to pure vermilion reference (inflection point at $580-605 \mathrm{~nm}) .{ }^{[33]}$ This shift could be explained by the presence of impurities, by specific morphological characteristics (particle size distribution and concentration of pigments) or by mixture with other red pigment. Such a high inflection point value has already been found for pure cinnabar by other teams. ${ }^{[34]}$ XRF and VNIR results suggest that small quantities of vermilion are mixed with lead white for the carnation

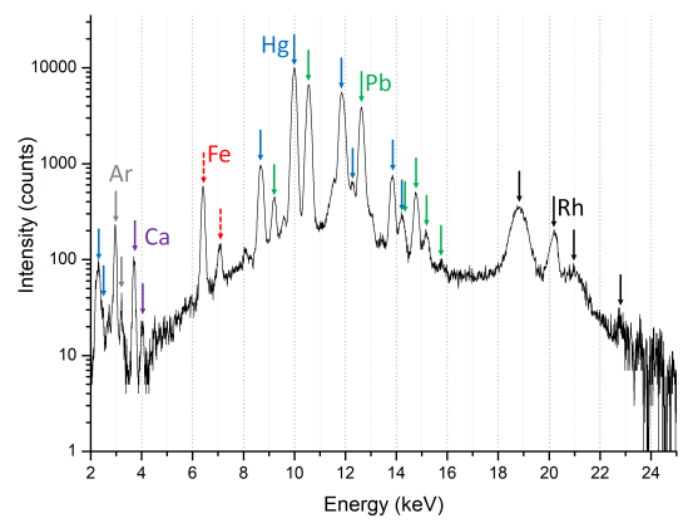

FIGURE 7 X-ray fluorescence (XRF) sum spectrum (60 pixels) extracted from the lips of the Child showing the presence of mercury. (Figures 8 and 10).

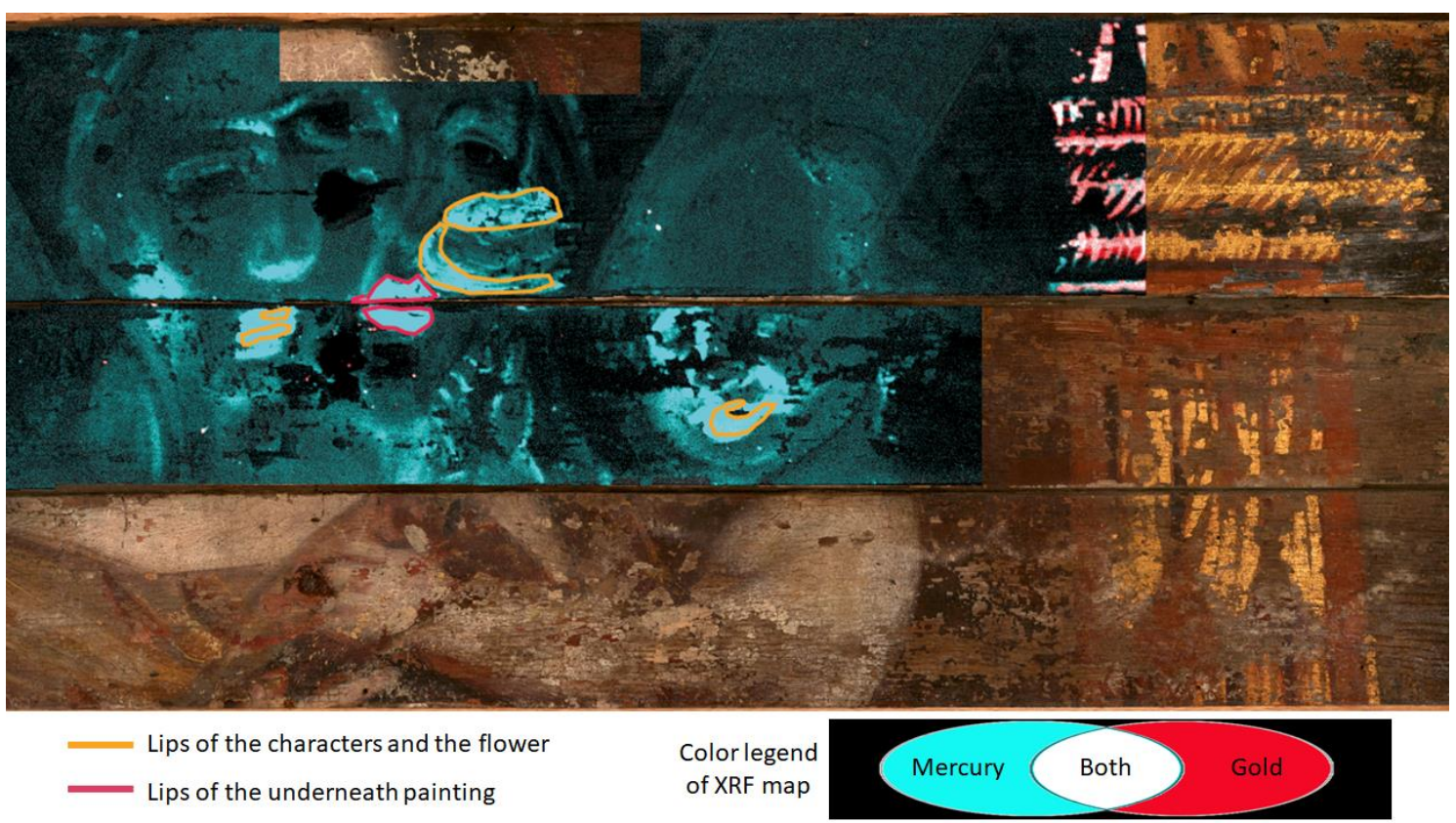

FIGURE 8 X-ray fluorescence (XRF) false color mapping. Gold (L $\alpha$ lines) is in red, mercury (L $\alpha$ lines) in blue, mix of both in white. Orange line underlines the lips of the characters and the flower on the surface, pink lines are the lips of the underneath painting. 


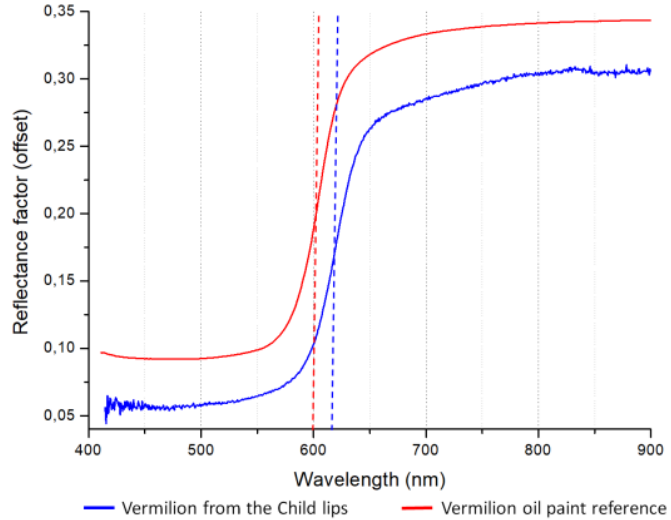

..... Inflection point $(615 \mathrm{~nm})$..... Inflection point (600 nm)

FIGURE 9 Visible and near infrared range (VNIR) reflectance spectrum (extracted from 100 pixels) from the Child lips showing the presence of vermilion compared to a reference of vermilion (Kremer)
MA-XRF maps highlight the shape of the flower in the right hand of the Child. The high concentration of lead and mercury indicates the presence of vermilion and lead white used for lights (also confirmed by VNIR and SWIR hyperspectral data). The stem is easily discernable in black on the SWIR hyperspectral image, while looking directly at this painting the stem is not easily discernable from the dark background (Figure 11). As the reflectance spectrum in the stem is almost zero, it suggests that an absorbing material such as carbon black is used in this area. Due to the conservation state of the painting layers, it is difficult to determine the flower specie, but the shape of the petals suggests that it could be a rose.

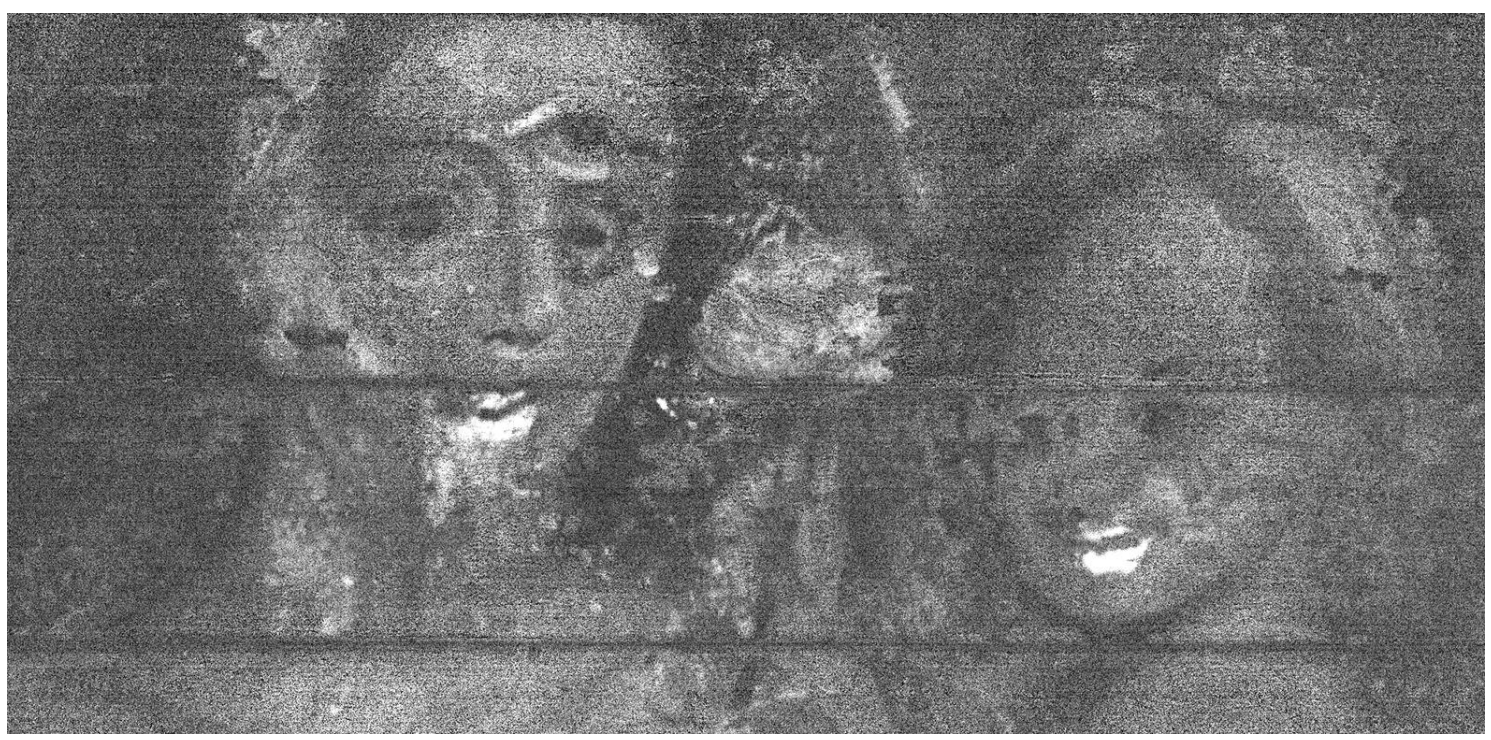

FIGURE $10 \quad$ Visible and near infrared range (VNIR) image extracted at $615 \mathrm{~nm}$ from the reflectance first derivative data cube. The white areas underline the high concentration of vermilion.

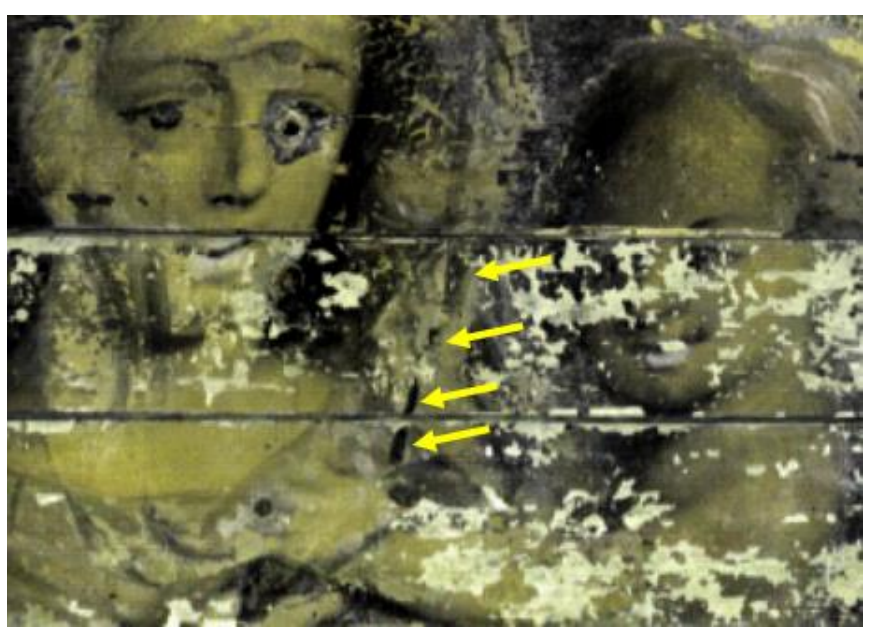

FIGURE 11 Short-wave infrared (SWIR) false color image (R=2177 nm, G=2204 nm, B=2347 nm). Yellow arrows indicate the stem of the flower. 


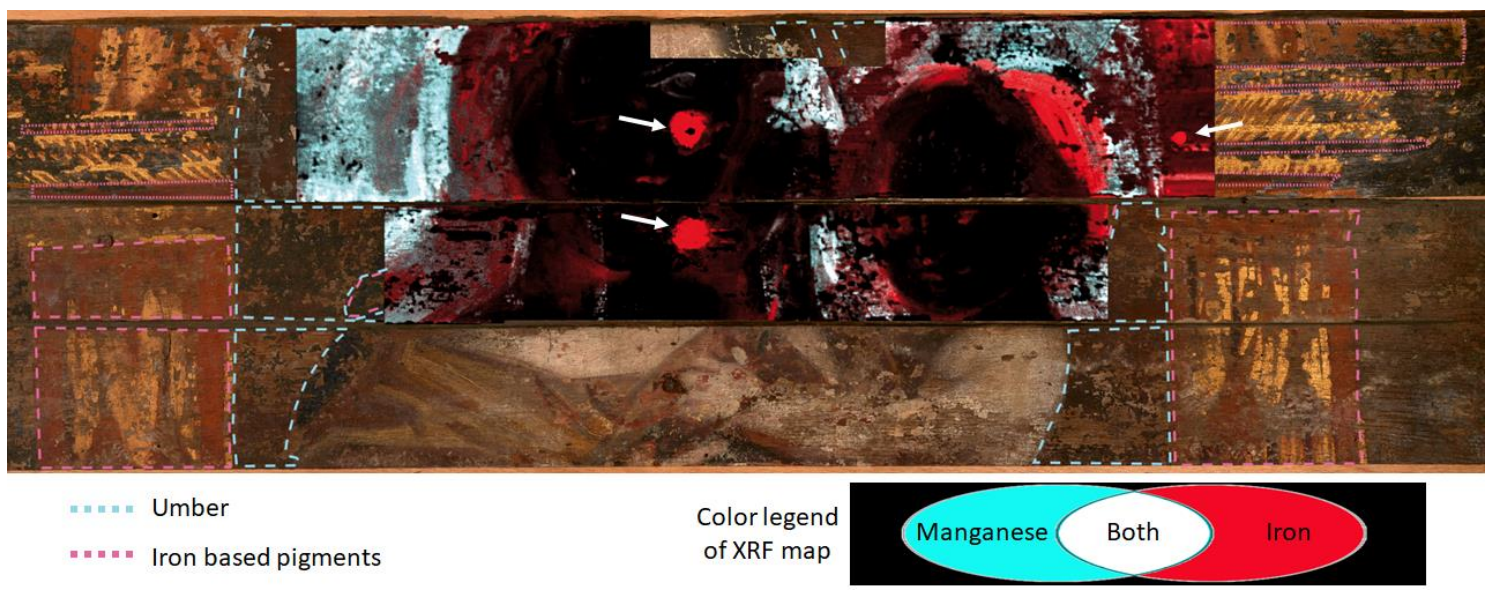

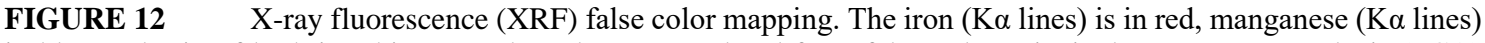
in blue and mix of both in white. Based on data extrapolated from false color principal components analysis (PCA) composite images, dotted pink lines highlight iron based pigments (hair and architectural columns), whereas dotted blue lines underline umber (the background).

The presence of manganese (Mn) and iron $(\mathrm{Fe})$ is the footprint of umber used for the background (Figures12 and 13). No hyperspectral imaging signals were detected due to the presence of highly absorbent black material (probably a carbon black).

The red pigment of the architectural columns is probably hematite, due to the presence of iron (Figures 12 and 14) and the specific characteristics observed on VNIR reflectance spectra (Figures 15 and 17). In these areas, the spectra show a characteristic shape due to the presence of $\mathrm{a}-\mathrm{Fe}_{2} \mathrm{O}_{3}$ as chromophore. ${ }^{[33]}$ However, different pigments (red ochre, burnt sienna, etc.) contain hematite. It is therefore not possible to identify more precisely the red iron

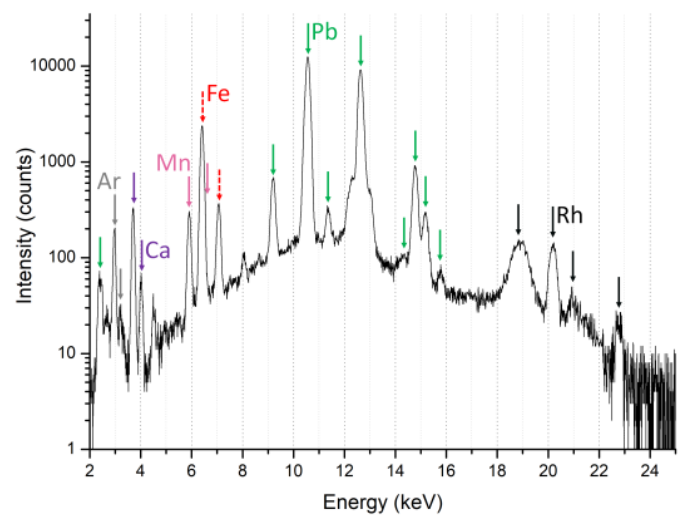

FIGURE 13 X-ray fluorescence (XRF) sum spectrum (52 pixels) extracted from the background showing the presence of iron and manganese composing umber. oxide pigment used here. Gold ( $\mathrm{Au}$ ) and mercury $(\mathrm{Hg})$ are present in the columns' decoration (Figures 8, 16 and 18). Most of the time, these two elements are correlated but it is possible to find small areas with only $\mathrm{Au}$ or only $\mathrm{Hg}$ (Figure19). Thus this golden material doesn't seem to be a gold-mercury amalgam. As no features specific to a mercury based pigment are visible in spectra extracted from VNIR hyperspectral data, mercury might not be on the surface but should come from an underlying layer. All these data rather attest to the use of gold applied on vermilion or cinnabar used as underpaint probably to give redder hue to the gold on the surface.

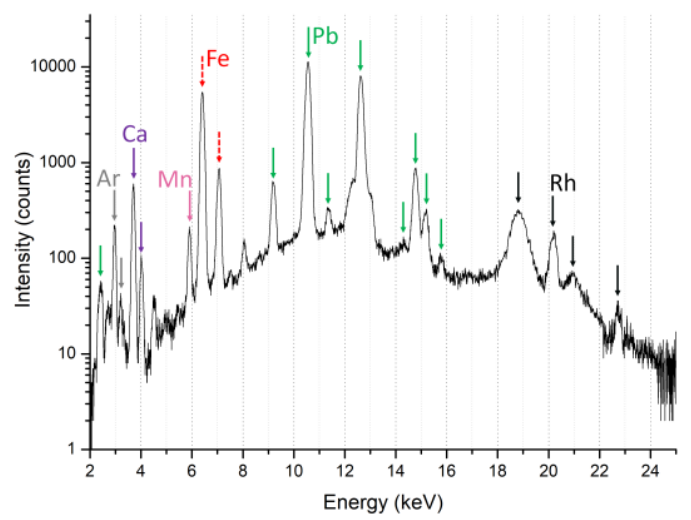

FIGURE 14 X-ray fluorescence (XRF) sum spectrum (58 pixels) extracted from the column showing the presence of iron. 


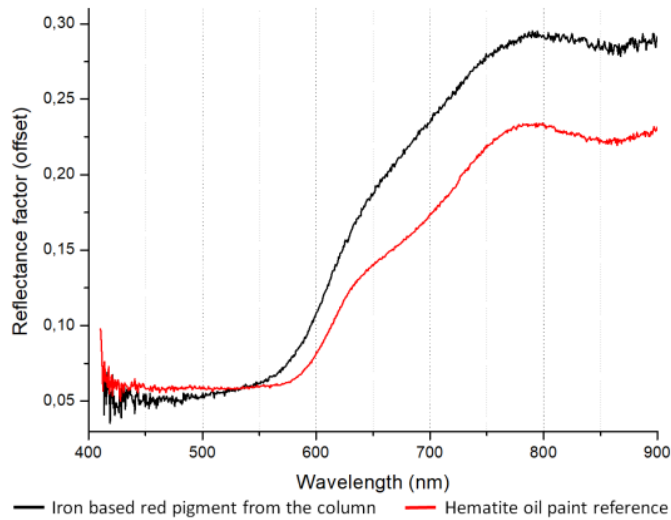

FIGURE $15 \quad$ Visible and near infrared (VNIR) reflectance spectrum (extracted from 100 pixels) from the column showing hematite compared to a reference of hematite (Kremer).

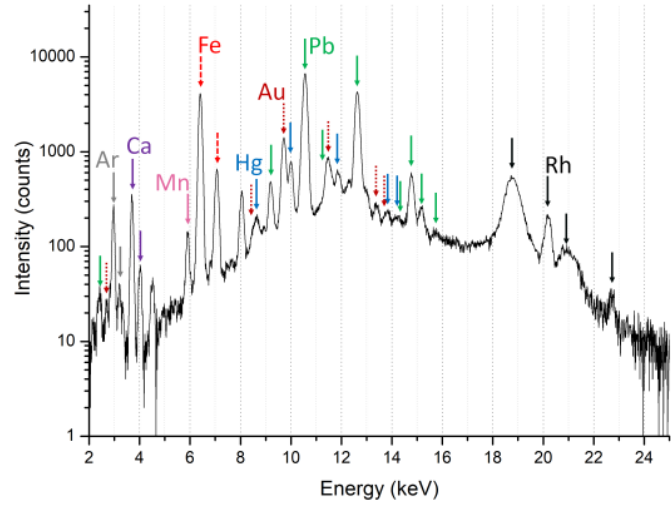

FIGURE 16 X-ray fluorescence (XRF) sum spectrum (60 pixels) extracted from the gold decoration on the column showing the presence of gold and mercury.

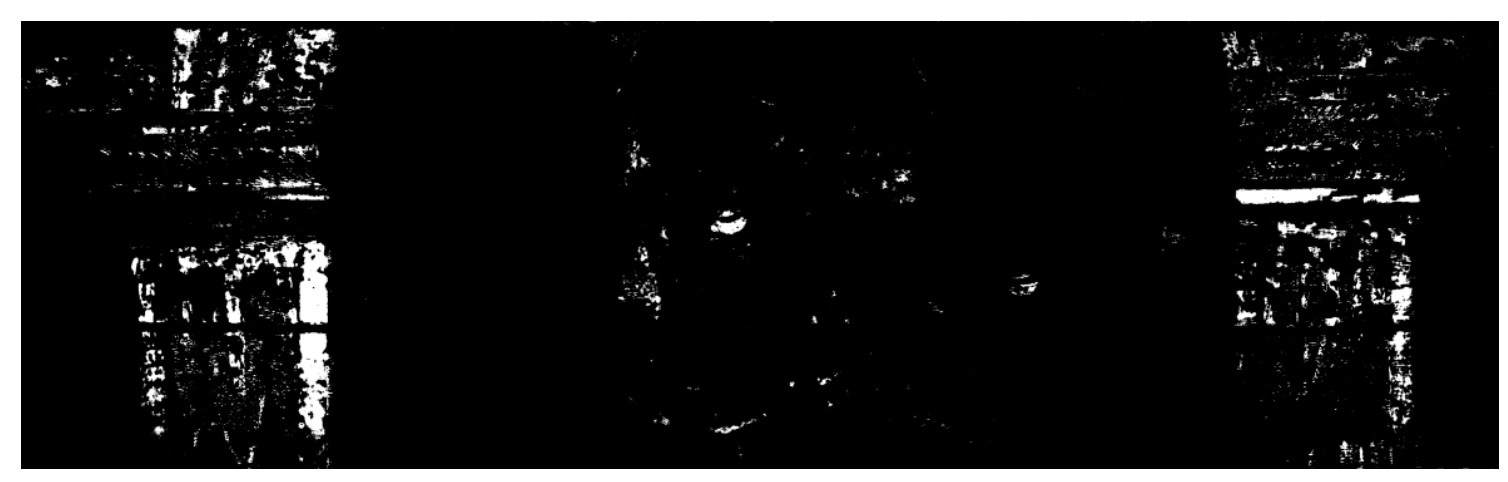

FIGURE 17 Spectral Angle Mapper (SAM) map of the visible and near infrared range (VNIR) image cube. A spectrum of hematite extracted from the right column is used as reference spectrum.

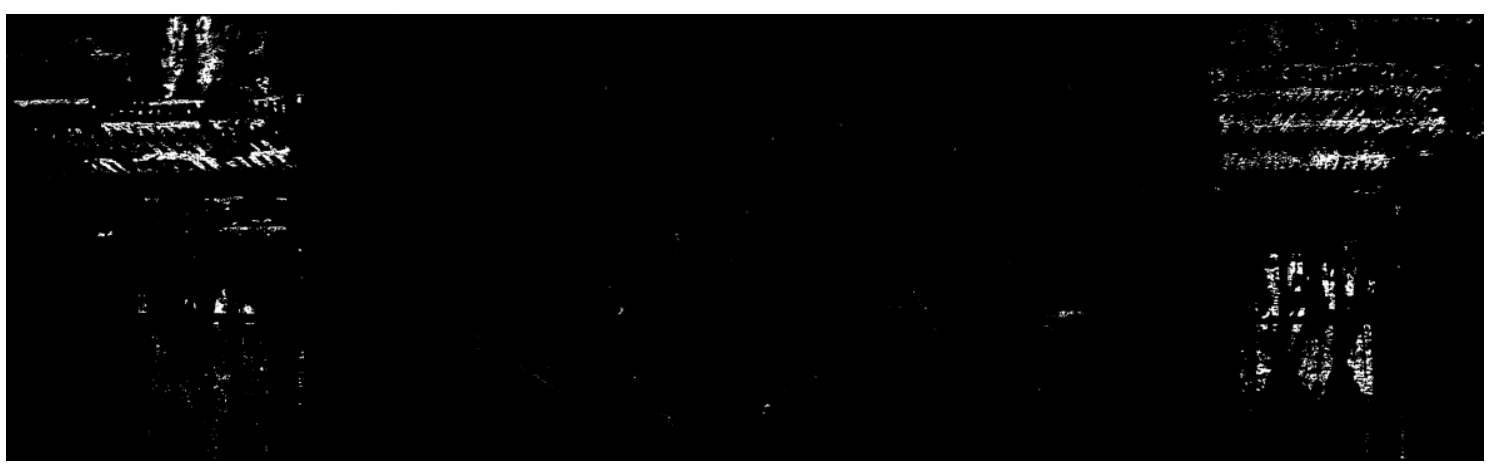

FIGURE 18 Spectral Angle Mapper (SAM) map of the visible and near infrared range (VNIR) image cube. A spectrum of gold area extracted from the right column is used as reference spectrum. 

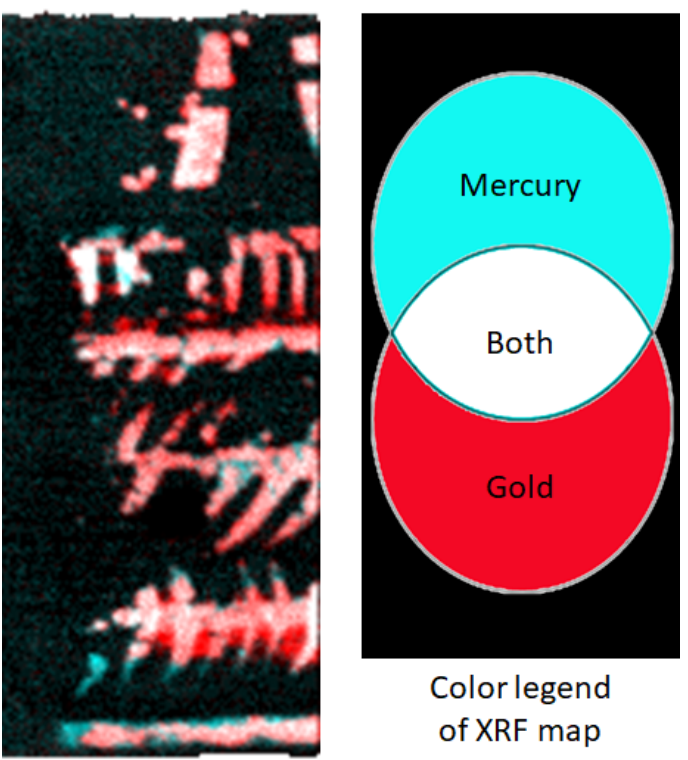

Color legend of XRF map

FIGURE 19 Detail of figure 8, X-ray fluorescence (XRF) false color mapping. Gold (L $\alpha$ lines) is in red, mercury (L $\alpha$ lines) in blue, mix of both in white.

The presence of nickel and cobalt in the hair of the Virgin, as well as the background between her face and the hand of the Child were assigned to smalt (Figures 20 and 21). The area where this pigment is detected is discontinued and covers some parts of the hair of the Virgin. As before, unfortunately, it is not possible to confirm this interpretation with hyperspectral imaging because the signal in this area is too weak probably due to the presence of a light-absorbing material like a carbon black.

In summary, the painter's pallet is classical for a paint of such period. Figure 22 resumes the results obtained for the 17 th century painting.

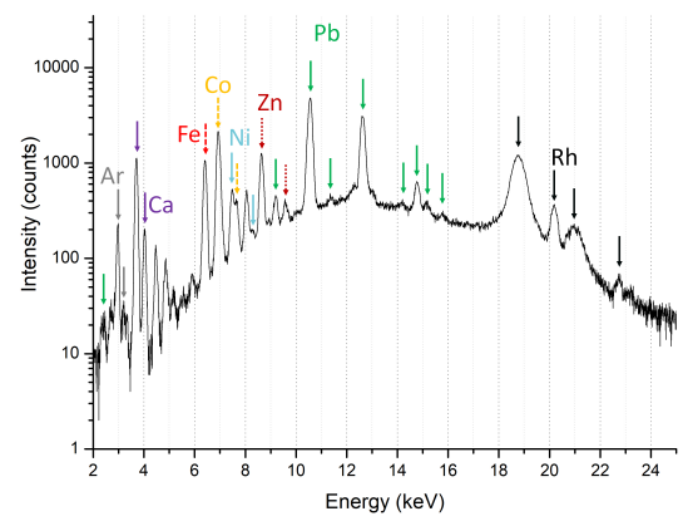

FIGURE 20 X-ray fluorescence (XRF) sum spectrum (60 pixels) extracted from the hair of the Virgin showing the presence of cobalt and nickel assigned to the smalt.

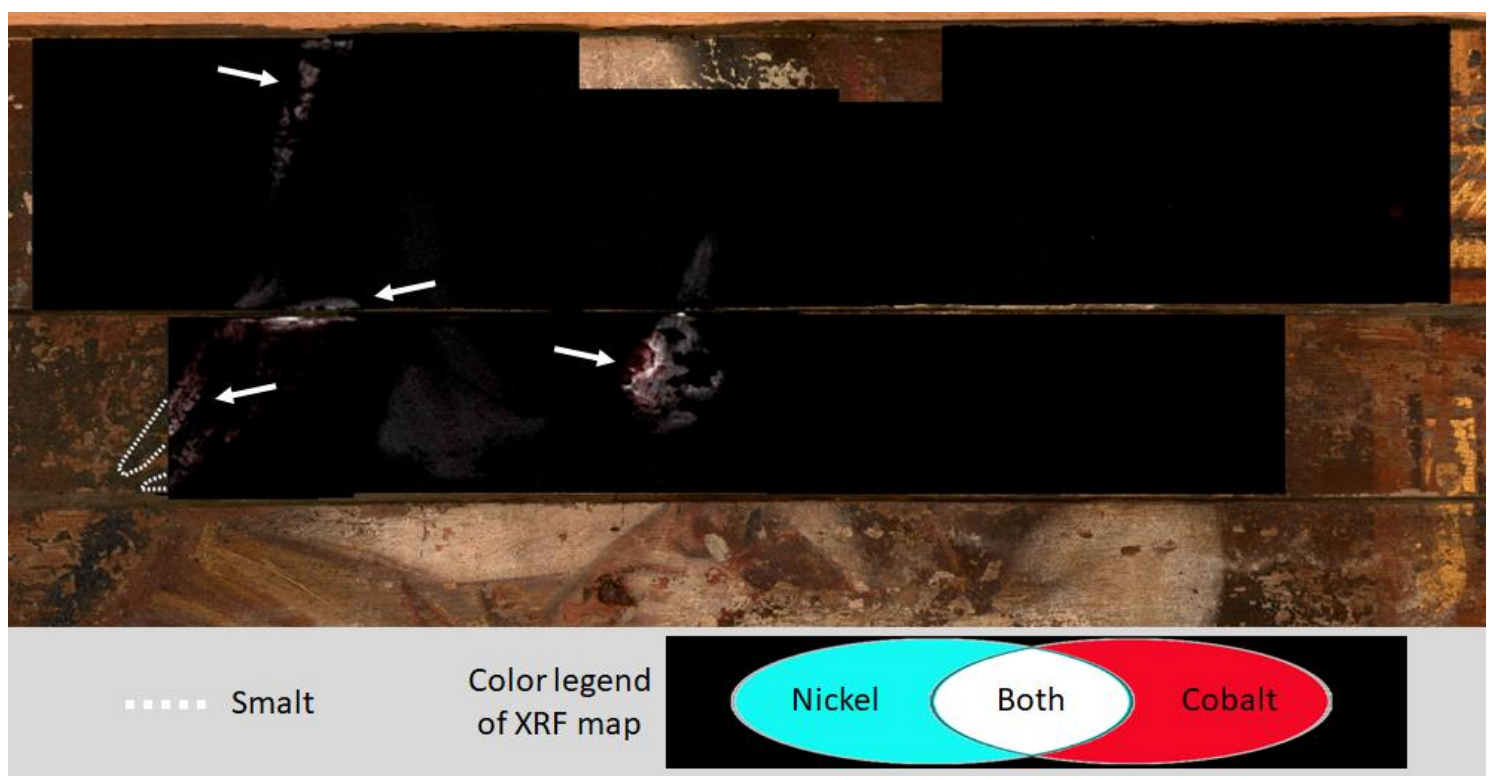

FIGURE 21 X-ray fluorescence (XRF) map in false color, cobalt ( $\mathrm{K} \alpha$ lines) appears in red, nickel (K $\alpha$ lines) is in blue and the mix of both in white. Based on data extrapolated from false color principal components analysis (PCA) composite images, the dotted white line and the white arrows show the area with cobalt blue. 


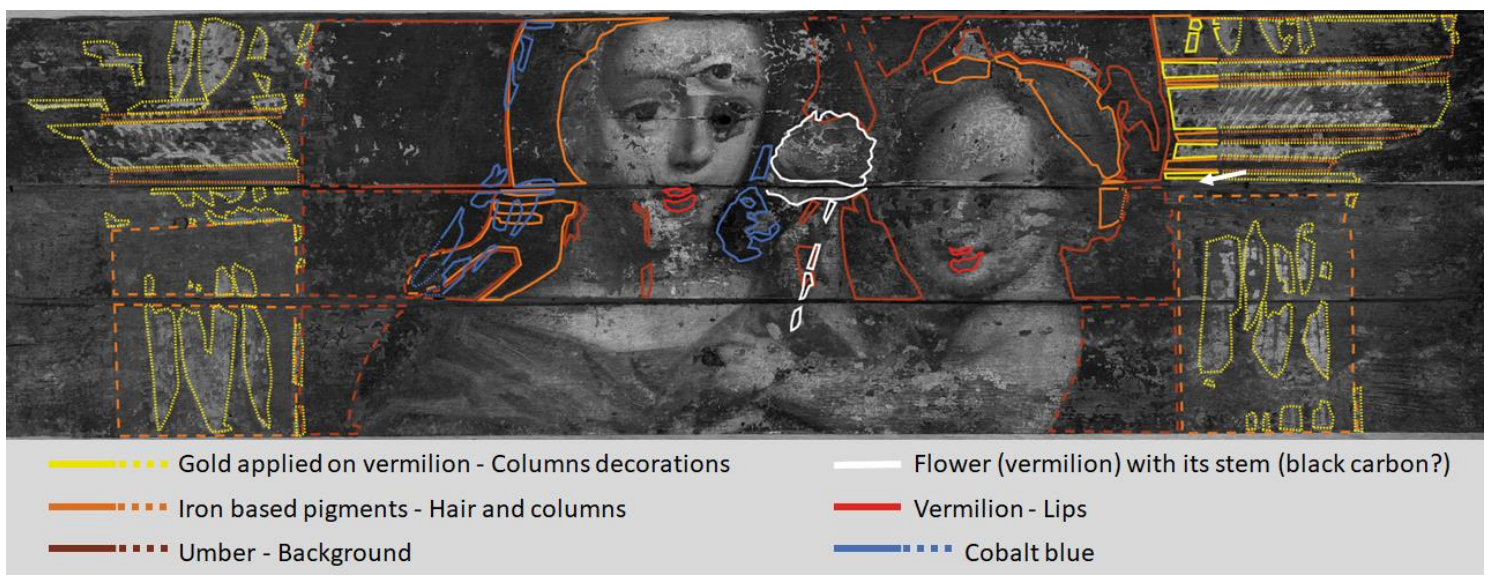

FIGURE 22 Schematic interpretation of the 17th century painting.

MA-XRF also reveals the presence of barium in different areas: on the carnation of the face and neck of the Virgin, on the shoulder of the Child, both on their hair and some parts of the flower (Figures 23 and 24). The pigment used is rather the barium white $\left(\mathrm{BaSO}_{4}\right)$ than the lithopone $\left(\mathrm{ZnS} \cdot \mathrm{BaSO}_{4}\right)$, because zinc was not detected there. In the PCA image in false color (Figure 25), the green color of the dress is the same as on the hair of the Virgin where barium white is identified by XRF analysis. Reflectance spectra of the two areas confirmed this similarity (extracted from VNIR hyperspectral data, not shown). The mixture used to restore these two areas could be similar not only for the presence of barium white but also because of the use of a specific binding or unidentified pigments. Indeed, the barium white was mixed with other undetermined pigments in order to achieve the restoration (Figure 26).

The upper part of the hair of the Child is covered by an orange mixture composed of barium white and an iron based pigment containing hematite (confirmed by VNIR hyperspectral data, not shown). The reflectance spectrum of this mixture is similar to those of the dress and the hair of the Virgin. This mixture does not cover all the hair and let appeared a sublayer characterized by the presence of the iron only, and which seems to correspond to the original hair of the Child (Figure 24).

Barium white started to be sold as a pigment for painting in 1810-1820, so this narrow period is a terminus post quem for the restoration. ${ }^{[35]}$ The restoration should have then been done between this date and the covering of the panels in 1869 by oil-painted linen canvas.

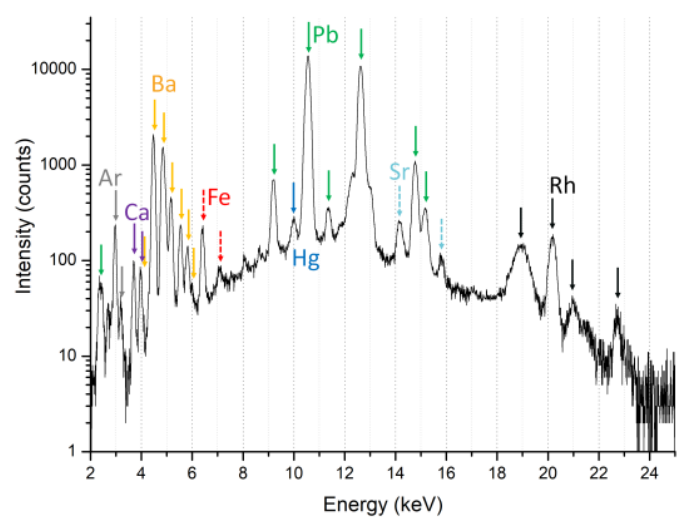

FIGURE 23 X-ray fluorescence (XRF) sum spectrum (62 pixels) extracted from the face of the Virgin showing the presence of barium.

Also, the traces of iron nails are clearly visible on XRF iron map (Figures 3 and 12) and on the SWIR hyperspectral image (not shown). The presence of chlorine is the footprint of the impact of corrosion of a nail on upper panel, which probably happened due to sea water salty aerosols, as the church is located in the region close to the ocean (Figure 27). 


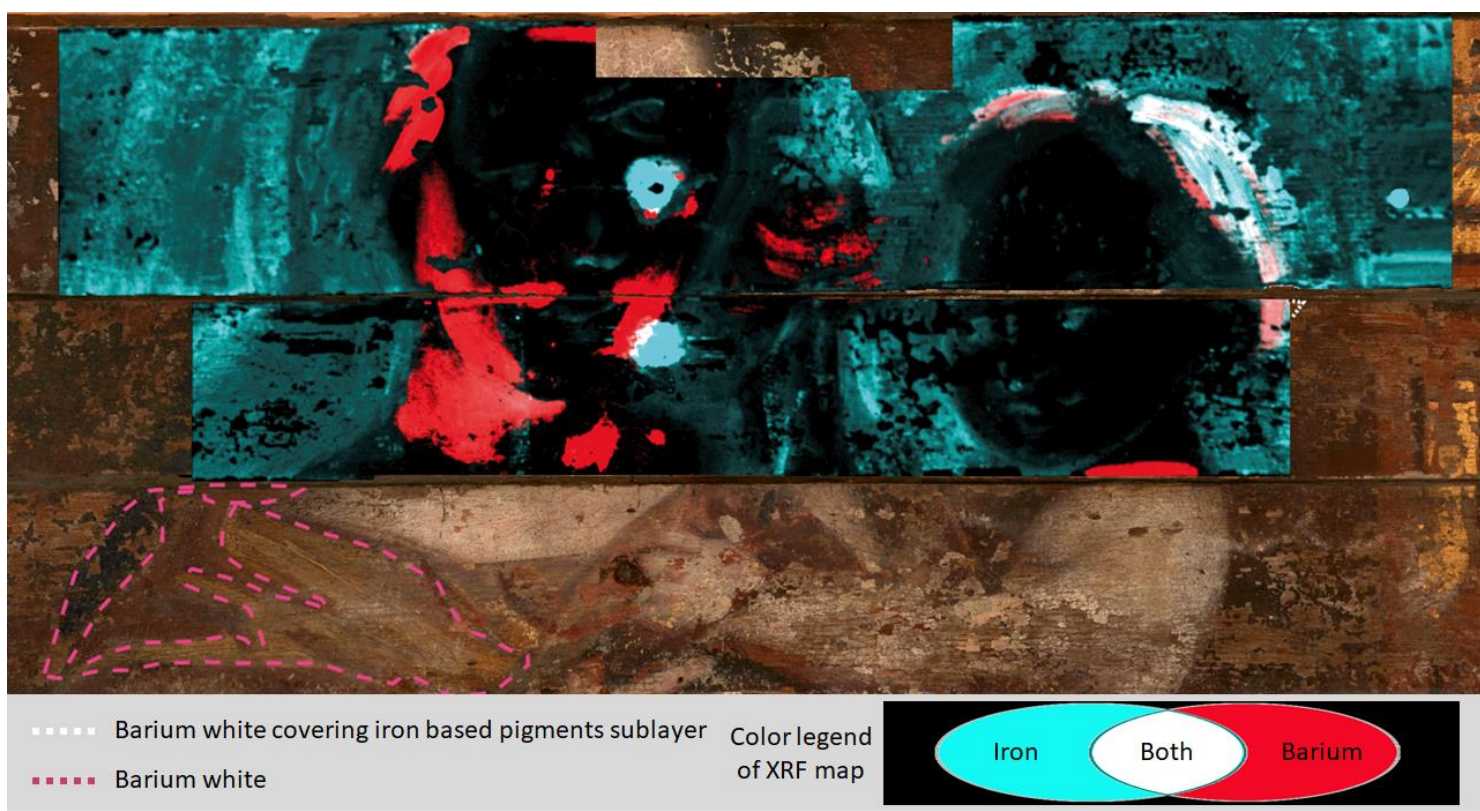

FIGURE 24 False color C-ray fluorescence (XRF) map. Barium (L $\alpha$ lines) is in red, iron (Ka lines) is in blue and mix of both in white. The red and white areas represent restorations with barium white. Based on data extrapolated from false color principal components analysis (PCA) composite images, the dotted white lines underline the restored part of the hair of the Child and the dotted pink lines are the clothes of the Virgin.

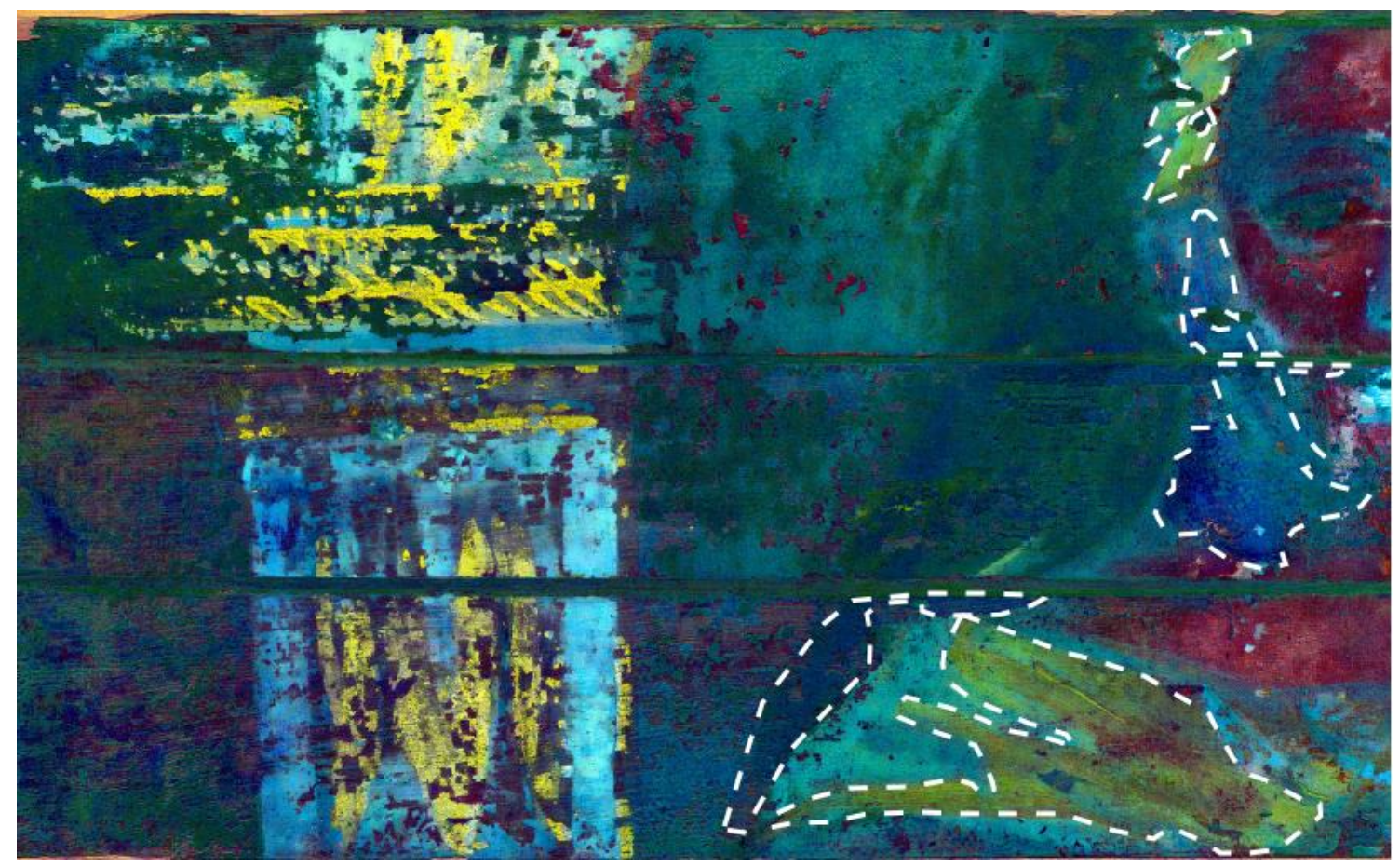

FIGURE 25 Principal components analysis (PCA) image in false color (LDS color space). Dotted white lines underline the restored areas containing barium based material. 


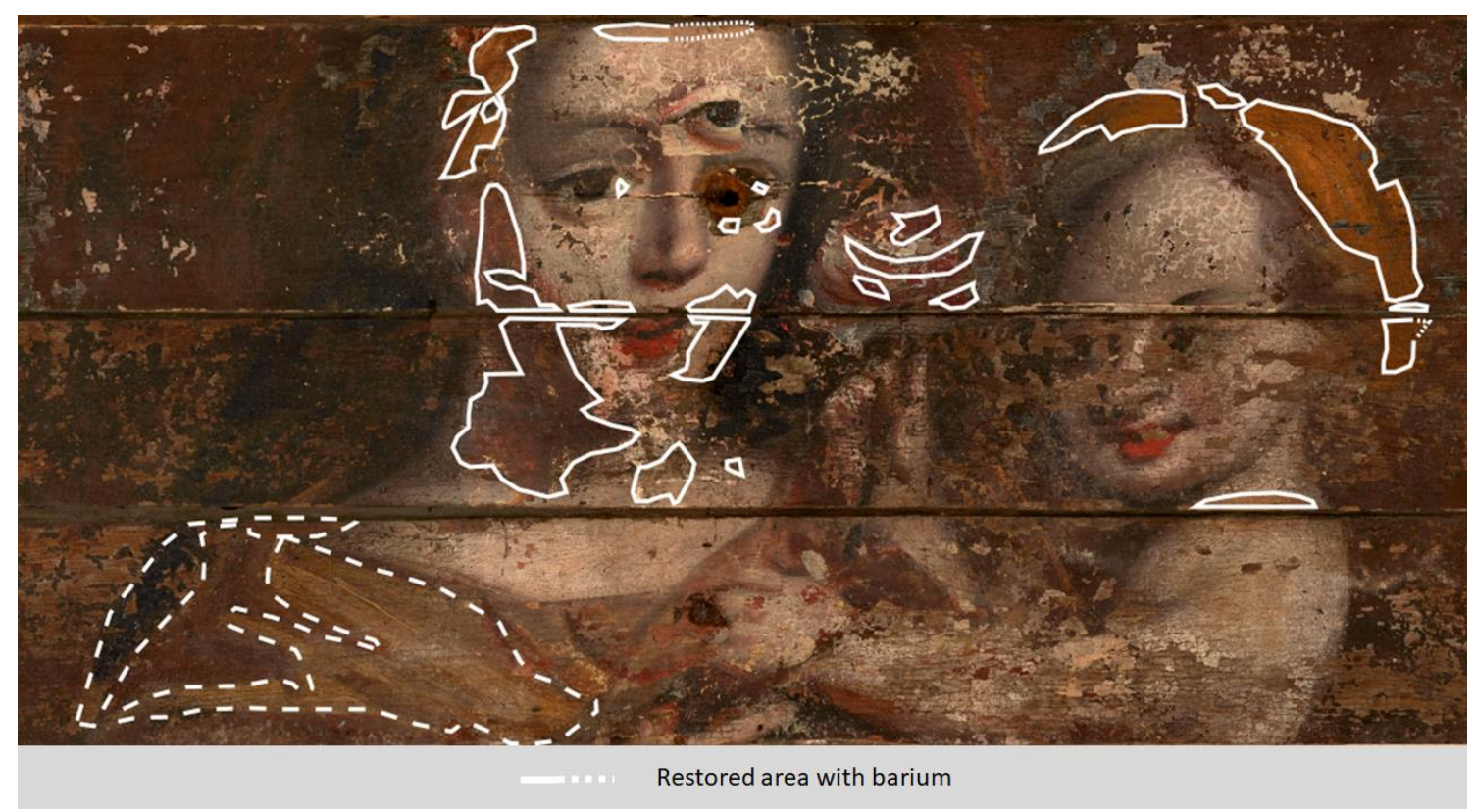

FIGURE 26 Visible (VIS) image. Semi-transparent white areas represent the restored areas containing barium based material on data obtained with X-ray fluorescence (XRF) (Figure 24) and principal components analysis (PCA) images (Figure 25).

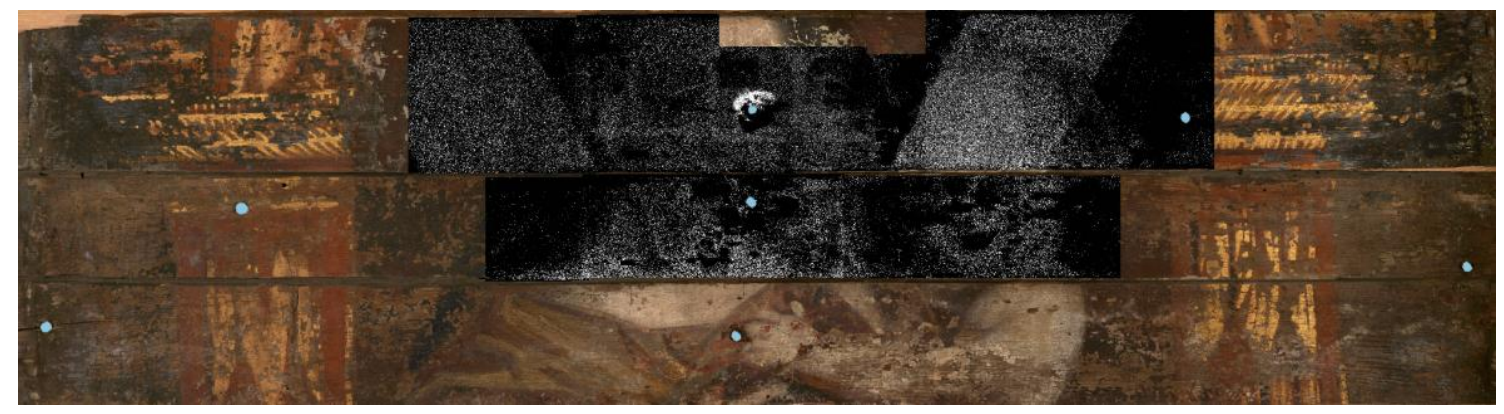

FIGURE 27 Chlorine (Ka lines) X-ray fluorescence (XRF) map. The white area underlines the high concentration of chlorine around a nail hole. Blue points indicate the positions of such holes.

\section{UNDERLYING PAINTING FROM THE END OF 15TH CENTURY}

Under the surface of the 17 th century paint, an older oil painting was discovered dating approximately from the end of 15 th century. Indeed, a rectangular uncovering window, made by conservators, shows the presence of an eye (Figure 1). Furthermore, on the XRF cartography of lead, a three-quarter portrait appears enclosed between two phylacteries (Figure 28). The phylacteries are visible only on the upper panel while the face is visible also on the two lower panels. They are painted using lead white pigment $(\mathrm{Pb})$ (Figure 28). The margins for the placement of the letters within the phylacteries were observed on $\mathrm{Pb}$ XRF map as darker lines. This is due to the mechanical removal of the lead white during the tracing of the margins.

Letters on phylacteries are probably paint with a carbon black mixed with a copper-based siccative pigment, making them pretty readable on the XRF copper $(\mathrm{Cu})$ map (Figure 29). The phylacteries like those we have seen on examined panels are partially visible in several parts of the entire vault, and especially above the image of the Virgin (Figure 30). 


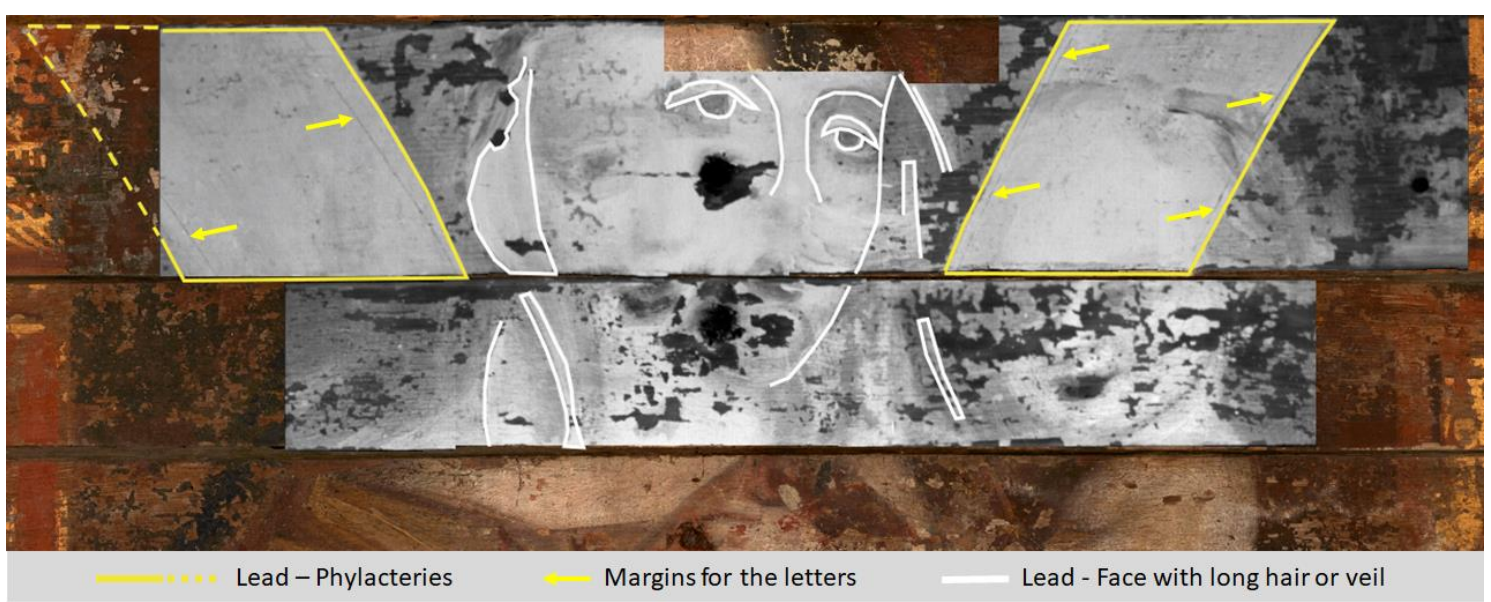

FIGURE 28 Lead (L $\alpha$ lines) X-ray fluorescence (XRF) map. The yellow lines represent the limits of subjacent phylacteries, yellow arrows show the margins tracings and the white lines highlight the underlying face with long hair or veil.

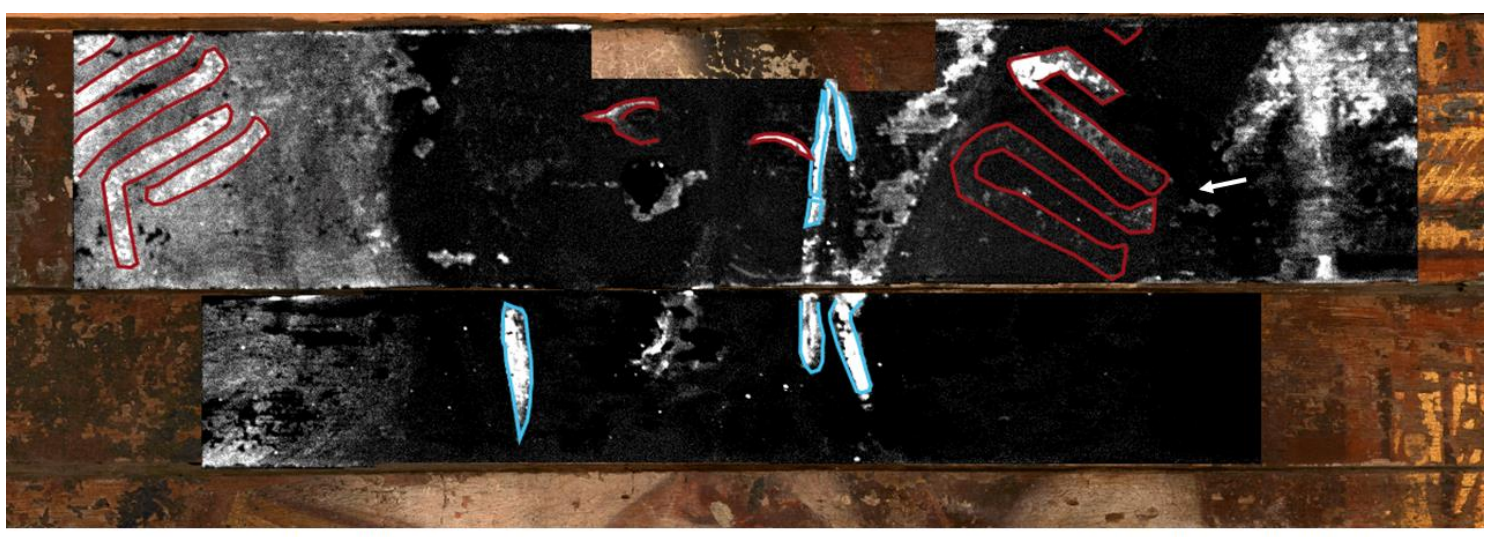

Copper - Letters of the phylacteries and eye contour

Copper - Possibly hair and veil shadows

FIGURE 29 X-ray fluorescence (XRF) mapping of copper (K $\alpha$ lines). The red lines represent the letters of the phylacteries and the eye contour of the underlying face while blue lines indicate underlying elements which can correspond to hair or veil shadows. 


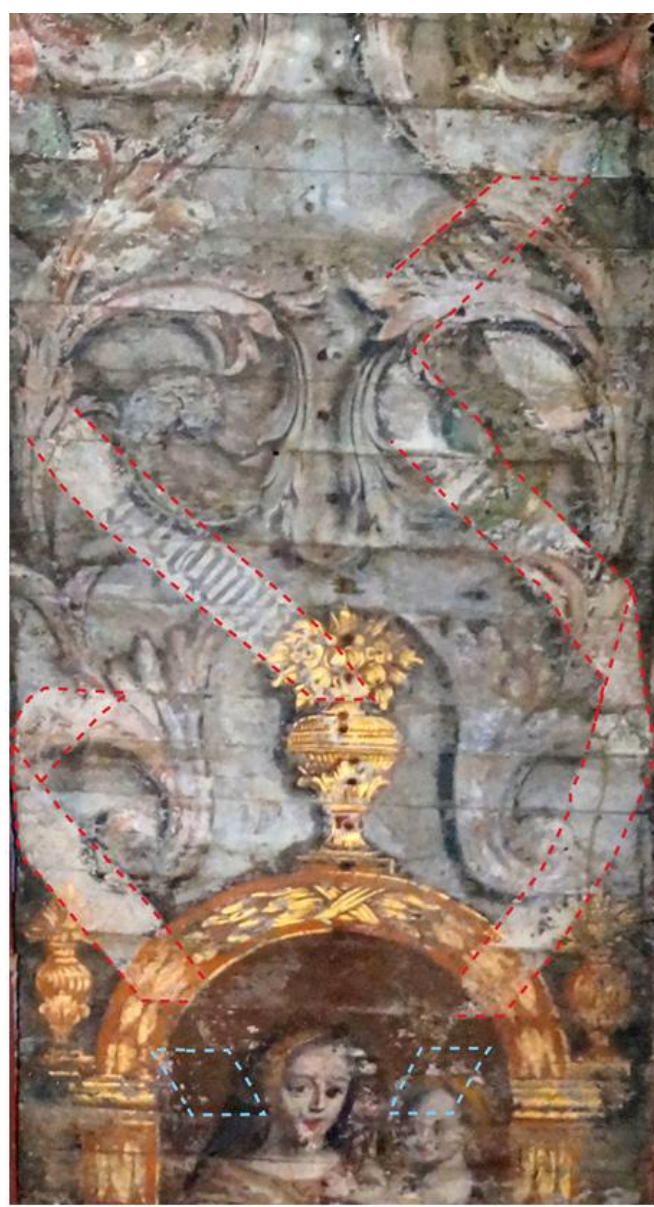

" . " . " Phylacteries actually visible on site

" " " " " Phylacteries detected by XRF Pb mapping

FIGURE 30 Phylacteries of the original painting from the end 15 th century under the 17 th century overpaint.
The XRF mapping of lead also reveals an underlying face with long hair or veil (Figure 28). Pupils, upper eyelids, the left eye arch and the bridge of the nose are visible. The eye contour is accentuated by a copper-based pigment (Figure 29). Several vertical oblong forms located on both sides of the Virgin face, detected with the XRF Cu mapping, appear as possible shadings of the hair or veil. The lips are painted with vermilion $(\mathrm{Hg}$ ) (Figure 8). This figure could be a representation of a Virgin whose hair is covered with a veil (Figure 31). XRF mapping of the additional lower panels could help us identifying it more precisely by revealing complementary parts of this image. This would allow us to discuss the possible continuity of the iconographic program between the original painting from the end of the 15 th century and the overlaid one from the 17 th century.

The phylacteries are unequivocally earlier than the 17th century painting but it is questionable whether they are contemporary with the 15 th century painting. In fact, the face is much enclosed between the phylacteries (Figure 31). Another example is visible on the vault with the phylacteries crossing behind the head of Saint Maurice. However, the visible Saint Maurice figure was painted during the 17th century campaign and it is impossible to say at the present moment if it covers another Saint's image, as we did not examine it. Since there is no written evidence of a third stage of painting, we will assume that all the hidden Virgin figure and phylacteries are contemporary with each other. A MA-XRF study or a full radiograph of the vault would be required to discuss this hypothesis. This would also allow us to check whether some of the panels have been replaced or moved over time, explaining the hypothetical discontinuities in the phylacteries.

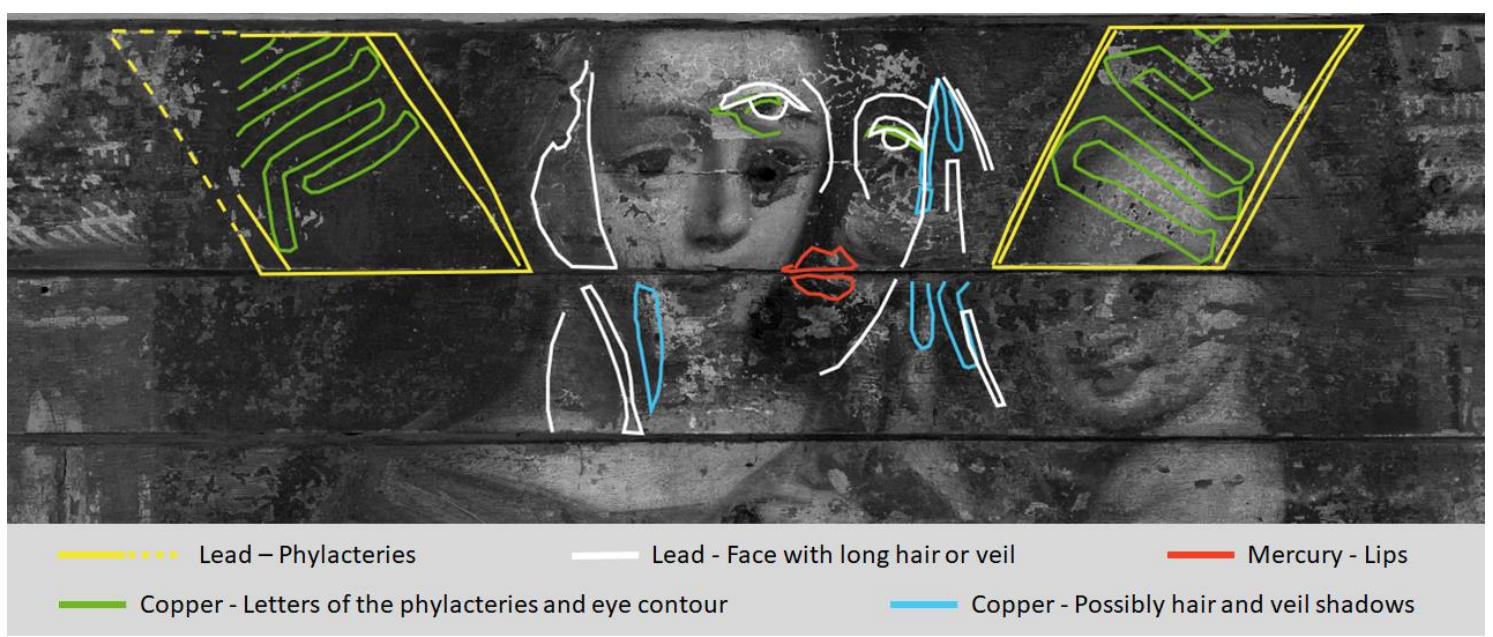

FIGURE 31 Schematic interpretation of the elements of the underneath painting from the end of 15th century.

\section{CONCLUSIONS}


The aim of this study was to detect the extent of the original underlying painting on wooden panels. In addition, this work aimed to describe the second painting from 17th century and its 19 th century restorations. For this purpose, three wooden panels portraying the Virgin with a Child were chosen as the target of this work. The goals were achieved using non-destructive imaging techniques, which allowed to both find the original painting and to characterize the later painting and its restoration.

The more ancient 15 th century painting is clearly detected by the MA-XRF mapping (Figure 31). The face of the Virgin and two phylacteries surrounding it were revealed by the lead XRF mapping while the copper map revealed the writing within the phylacteries. Largest campaign of analysis on the panels placed above the studied ones could allow to see larger text parts of the phylacteries conserved and to make their transcription.

Hyperspectral and multispectral techniques allowed faster imaging and covered larger area in relatively short time, circa 75 and $10 \mathrm{~min}$ respectively for whole 3 panels, in comparison with MA-XRF scanning, which needed more than $14 \mathrm{~h}$ for about $1 / 3$ of the surface. Hyper- and multispectral imaging confirmed, completed and allowed extrapolation of the XRF results of the examined panels. They particularly helped in understanding part of the painted iconography highly deteriorated like the case of the flower and its stem. Nonetheless, these techniques did not help revealing the original 15 th century painting.

Indeed, the complementarity of MA-XRF mapping, multi- and hyperspectral imaging is clearly underlined with this study for the second painting from the 17th century (Figure 22) and its 19th century restorations (Figure 26). In particular, figure 22 illustrates the complementary results obtained by the combination of those three techniques. Based on these results, it is indeed possible to distinguish, with non-invasive techniques, the different painting and restoration campaigns in order to help the conservators in their decision to uncover or not the 15 th century original painting.

The results get some information on the pigments used by the painters of the 15th and 17 th century paintings. They show an interesting use of gold underlaid by a mercury based pigment used for the decoration of columns on both sides of the painted panels. They also allow dating the restoration work as done between 1810 and 1869 giving a terminus post quem due to the presence of barium white. Nevertheless, some questions are still pending, such as whether there is a lack of continuity of the phylacteries on the middle and lower parts of studied panels, or of the existence of the Child figure in the 15th century painting, which could attest the continuity of pictorial program in overlying painting. We expect that the answers to these questions could be given after the examination in situ of a larger area of the vault, using preferentially a smaller MA-XRF portable device.

\section{ACKNOWLEDGEMENTS}

The authors would like to gratefully acknowledge the financial support of the Fondation des sciences du patrimoine (Labex Patrima, ANR-10-LABX-0094-01). This work was also supported by the Paris Ile-de-France Region through Domaine d'intéret majeur (DIM) programme: "Matériaux anciens et patrimoniaux".

\section{REFERENCES}

[1] Anonymous, Le Quillio (22) - Église paroissiale - Étude des supports et des décors des lambris sous-jacents aux toiles, Nantes, France: Arthema Restauration, 2017.

[2] F. Le Bec, A. Kowalczyk, Le Quillio (22) Eglise Notre Dame de la Délivrance. Etude préalable à la restauration des décors $d u$ cour et de la chapelle du Rosaire, 2017.

[3] B. Borg, M. Dunn, A. Ang, et C. Villis, JCH 2020, 44, 239-259.

[4] S. Rita Amato, A. Burnstock, M. Cross, K. Janssens, F. Rosi, L. Cartechini, R. Fontana, A. Dal Fovo, M. Paolantoni, C. Grazia, A. Romani, A. Michelin, C. Andraud, A. Tournié, J. Dik, X-Ray Spectrom. 2019, 48, 282-292.

[5] K. Laclavetine, C. Boust, L. Clivet, A. S. Le Hô, E. Laval, R. Mathis, M. Menu, E. Pagliano, X. Salmon, V. Selbach, C. Vrand, S. Lepape, Microchem. J. 2019, 144, 419430.

[6] K. A. Dooley, E. M. Gifford, A. van Loon, P. Noble, J. G. Zeibel, D. M. Conover, M. Alfeld, G. Van der Snickt, S. Legrand, K. Janssens, J. Dik, J. K. Delaney, Herit. Sci. 2018, 6, 1-15.

[7] J. K. Delaney, D. M. Conover, K. A. Dooley, L. Glinsman, K. Janssens, M. Loew, Herit. Sci. 2018, 6, 1-12.

[8] a)M. Alfeld, L. de Viguerie, Spectrochim. Acta Part B 2017, 136, 81-105. b)J. K. Delaney, K. A. Dooley, R. Radpour, I. Kakoulli, Sci. Rep. 2017, 7, 1-12.

[9] G. Van der Snickt, A. Martins, J. K. Delaney, K. Janssens, J. Zeibel, M. Duffy, C. McGlinchey, B. Van Driel, J. Dik, Appl. Spectrosc. 2016, 70, 57-67.

[10] F. Albertin, A. Astolfo, M. Stampanoni, E. Peccenini, Y. Hwu, F. Kaplan, G. 
Margaritondo, X-Ray Spectrom. 2015, 44, 93-98.

[11] G.J. Tserevelakis, P. Siozos, A. Papanikolaou, K. Melessanaki, G. Zacharakis,Ultrasonics 2019, 98, 94-98.

[12] J. R. Mansfield, M. Attas, C. Majzels, E. Cloutis, C. Collins, H. H. Mantsch, Vib. Spectrosc. 2002, 28, 59-66.

[13] M. Caccia, L. Bonizzoni, M. Martini, R. Fontana, V. Villa, A. Galli, Appl. Spectrosc. 2020, 1-34.

[14] E. Hernández, K. Laclavetine, R. Alvarado, A. Kriznar, M. del Valme Muñoz, M. Vega, E. Arroyo, J.L. Ruvalcaba Sil, M.A. Respaldiza, art'14 Conference, Madrid 2014, 1-8.

[15] S. Joo Kim, F. Deng, M. S. Brown, Pattern Recogn. 2011, 44, 1461-1469.

[16] C. Cucci, J. K. Delaney, M. Picollo, Acc. Chem. Res. 2016, 49, 2070-2079.

[17] E. Ravaud, L. Pichon, E. Laval, V. Gonzalez, M. Eveno, T. Calligaro, Appl. Phys. A 2016,122, 17.

[18] M. Alfeld, W. De Nolf, S. Cagno, K. Appel, D. P. Siddons, A. Kuczewski, K. Janssens, J. Dik, K. Trentelman, M. Walton, A. Sartorius, J. Anal. At. Spectrom. 2013, 28, 40-51.

[19] K. Trentelman, K. Janssens, G. van der Snickt, Y. Szafran, A.T. Woollett, J. Dik, Appl. Phys. A 2015, 121, 801-811.

[20] Multivariate Statistical Analysis of image series (MSA_514), ImageJ, June 17, 2020 https://imagej.net/plugins/inserm514/Docu mentation/MSA_514/MSA.html

[21] J.A. Richards, Remote sensing digital image analysis: an introduction, Springer-Verlag, Berlin, Germany 1986.

[22] I. Domingo, B. Carrión, S. Blanco, J. L. Lerma, Digit. Appl. Archaeol. Cult. Heritage 2015, 2, 79-88.

[23] F. A. Kruse, A. B. Lefkoff, J. W. Boardman, K. B. Heidebrecht, A. T. Shapiro, P. J. Barloon, A. F. H. Goetz, JPL, Summaries of the Third Annual JPL Airborne Geoscience Workshop. Volume 1: AVIRIS Workshop 1992, 23-25.

[24] H. Deborah, N. Richard, J. Y. Hardeberg, IEEE J-STARS 2015,8, 3224-3234.

[25] J. W. Boardman, Proceedings of the Summaries of the Seventh JPL Airborne Geoscience Workshop 1998, 55-56.

[26] J. W. Boardman, F. A. Kruse, IEEE Trans. Geosci. Remote. Sens. 2011, 49, 41384152.

[27] J. K. Delaney, J. G. Zeibel, M. Thoury, R. Littleton, M. Palmer, K. M. Morales, E. R. de la Rie, A. Hoenigswald, Appl. Spectrosc. 2010, 64, 584-594.
[28] M. Alfeld, J. Vaz Pedroso, M. van Eikema Hommes, G. Van der Snickt, G. Tauber, J. Blaas, M. Haschke, K. Erler, J. Dik, K. Janssens, J. Anal. At. Spectrom. 2013, 28, 760-767.

[29] M. Alfeld,Datamuncher, Source Forge, June 17, 2020.

https://sourceforge.net/projects/datamunch er/files/

[30] M. Alfeld, K. Janssens, J. Anal. At. Spectrom. 2015,30, 777-789.

[31] M. Hamoury, La peinture religieuse en Bretagne aux XVIIe et XVIIIe siècles, Presses universitaires de Rennes, Rennes, France 2010.

[32] F. Le Pottier Ed., Le Patrimoine religieux Le Quillio, Terre sacrée, Dupenher, SaintBrieuc, France 2011.

[33] M. Aceto, A. Agostino, G. Fenoglio, A. Idone, M. Gulmini, M. Picollo, P. Ricciardi, J. K. Delaney, Anal. Methods 2014, 6, 14881500 .

[34] X. Ma, H. Pasco, M. Balonis, I. Kakoulli, Sustainability 2019, 11, 1-20.

[35] R. L. Feller, A. Roy, Artist's pigments - A handbook of their history and characteristics, Vol. 1, Cambridge University Press, Cambridge, England 1986. 